\title{
Performance Comparison of Low Temperature and Chemical Absorption Carbon Capture Processes in Response to Dynamic Electricity Demand and Price Profiles
}

\author{
Seyed Mostafa Safdarnejad \\ Brigham Young University \\ John Hedengren \\ Brigham Young University, john.hedengren@byu.edu \\ Kody M. Powell \\ University of Utah
}

Follow this and additional works at: https://scholarsarchive.byu.edu/facpub

Original Publication Citation

https://www.sciencedirect.com/science/article/abs/pii/S030626191830967X

\section{BYU ScholarsArchive Citation}

Safdarnejad, Seyed Mostafa; Hedengren, John; and Powell, Kody M., "Performance Comparison of Low Temperature and Chemical Absorption Carbon Capture Processes in Response to Dynamic Electricity Demand and Price Profiles" (2018). Faculty Publications. 4160.

https://scholarsarchive.byu.edu/facpub/4160

This Peer-Reviewed Article is brought to you for free and open access by BYU ScholarsArchive. It has been accepted for inclusion in Faculty Publications by an authorized administrator of BYU ScholarsArchive. For more information, please contact ellen_amatangelo@byu.edu. 


\title{
Performance Comparison of Low Temperature and Chemical Absorption Carbon Capture Processes in Response to Dynamic Electricity Demand and Price Profiles
}

\author{
Seyed Mostafa Safdarnejad \\ Department of Chemical Engineering, 3290 MEB, University of Utah, Salt Lake City, UT 84112, USA \\ John D. Hedengren \\ Department of Chemical Engineering, 350 CB, Brigham Young University, Provo, UT 84602, USA \\ Kody M. Powell \\ Department of Chemical Engineering, 3290 MEB, University of Utah, Salt Lake City, UT 84112, USA
}

\begin{abstract}
Current projections to the year 2050 reveal that fossil fuels will remain the main source of energy generation. To achieve the target limits of carbon dioxide emission, set by national and international policies, carbon capture will play a key role. Modeling and optimization of various carbon capture technologies such as precombustion, oxy-fuel, and post-combustion, when integrated with coal-fired power plants, have been researched extensively in literature. Research on the integration of power generation with capture technologies regarding comparisons between the different schemes in response to dynamic inputs is lacking. This work provides a comparison between a low temperature carbon capture and a chemical absorption process in response to a dynamic electricity demand and price profile and in the presence of an intermittent wind power supply. The objective in this work is to meet the overall electricity demand of residential users and the carbon capture process while the total operating cost associated with the integrated system of power generation and carbon capture is minimized. This comparison includes scenarios with and
\end{abstract}

${ }^{*}$ Corresponding author. Tel.: +1-801-581-3957 
without energy storage associated with each capture technology. It is observed that in both integrated systems, with and without energy storage, the overall electricity demanded by the capture process and residential users is supplied by a combination of coal and wind power. For the case without energy storage, the total operating cost and energy demand of the low temperature carbon capture, based on a similar amount of captured carbon dioxide, are $4.3 \%$ and $20.5 \%$ less than that of chemical absorption, respectively. For the scenario with energy storage, the low temperature carbon capture requires $32.34 \%$ less energy to capture similar amounts of carbon dioxide while incurring $9.09 \%$ less overall operational cost.

Keywords: Power generation, Carbon capture, Low temperature carbon

capture, Chemical absorption, Dynamic optimization, Dynamic

inputs

\section{Introduction}

Many countries rely on electricity generation from fossil fuels to meet a significant portion of their energy demands. In the United States, for instance, the projections from the US Energy Information Administration (EIA) show a continuing dependence of the US power sector to fossil fuels in 2050 by $56 \%$ with Clean Power Plan (CPP) regulations in place (62\% without CPP), compared to $70 \%$ in 2015 . Because combustion of fossil fuels generates carbon dioxide $\left(\mathrm{CO}_{2}\right)$, the power sector will remain one of the major $\mathrm{CO}_{2}$ emitting sources in the US with $23 \%$ contribution in 2050 with CPP regulations in place (26\% without CPP), compared to $26 \%$ in 2015, according to EIA Annual Energy Outlook 2017 [1]. Global and the US national $\mathrm{CO}_{2}$ emissions will cause substantial environmental and public health issues, regardless of the fate of regulations such as CPP. According to reports from the US Environmental Protection Agency (EPA) [2] and Intergovernmental Panel on Climate Change (IPCC) [3, increasing concentrations of $\mathrm{CO}_{2}$ and other greenhouse gases endanger the health and welfare of current and future generations by causing global warming, harm to agriculture and forests, climate change, and ecosystem damage.

Countries around the world have implemented policies aimed to reduce carbon 
dioxide emissions from different sources [4,5]. Among all carbon emission sources, coal fired power plants contributed $42 \%$ of all $\mathrm{CO}_{2}$ emissions in 2012 [6]. As a significant contributor to carbon dioxide emissions, $\mathrm{CO}_{2}$ from coal-fired power plants must be mitigated to meet carbon dioxide standards defined by policy. The problem of reducing carbon dioxide emissions from coal-fired power plants has been addressed and documented in literature. Pre-combustion [7, 8, 9], oxy-fuel [10, 11], and post-combustion [6, 12, $13,14,15,16,17,18,19,20,21,22,23,24,25,26]$ carbon capture processes have been researched to reduce carbon dioxide emissions from coal-fired power plants. Extensive research has been conducted on modeling and improving individual carbon capture schemes [27, 28, 29, 30], but lacks much regarding comparison between the different schemes in response to dynamic inputs [31. For instance, [32] considered the techno-economic study of two super critical circulating fluidized bed (CFB) power plants when integrated with oxycombustion and Ethanolamine (MEA)-based post-combustion processes to separate $\mathrm{CO}_{2}$. This study compared the operating and capital costs, cost of electricity, and $\mathrm{CO}_{2}$ penalty when generating a constant power output. Dynamic investigation of each integrated system was also limited to start-up and shutdown procedures. Net efficiency comparison was also considered between oxy-fuel, pre- and post-combustion-based carbon capture technologies when coupled with Integrated Gasification Combined Cycle (IGCC) plants [33. The pre-combustion process considered in this analysis was based on hot gas clean-up, membrane-enhanced CO conversion, and $\mathrm{CO}_{2}$ condensation while the combination of calcination - carbonation loops, hot gas clean-up, and oxygen membranes constituted the post-combustion capture process. This comparison was also based on constant inputs to the power plant to generate a time-invariant power output. Other studies also compared the techno-economic performance of different integrated systems, consisting of various configurations of thermal power plants and post-combustion, pre-combustion, and oxy-fuel combustion technologies, to produce time-invariant power output $34 \quad 35$ 36, 37, 38, 39, 40, 41, 42. With the increasing penetration of renewable sources into the power grid, however, thermal power plants experience a significant increase in the number of load ramps to compensate for the intermittent behavior of renewable 
sources $43,44,45,46$. It is, thus, critical to investigate the performance of integrated systems of thermal power plants and carbon capture in response to dynamic circumstances that they may experience. This work compares the dynamic performance of a coal-fired power plant equipped with a novel low temperature carbon capture (LTCC) process with that of a conventional chemical absorption process, when both hybrid systems are subject to time-of-day electricity prices, dynamic electricity demand, and intermittent wind power. The LTCC process considered in this work is a novel technology that has an external cooling loop and requires less energy than most traditional capture processes at similar capture rates. The second capture process is an amine-based chemical absorption system, which is a relatively mature technology. Comparison of the techno-economic performance of the LTCC process with chemical absorption, to produce time-variant power output, and in response to dynamic inputs, is considered for the first time in this paper. This work also provides an optimization framework and demonstrates the benefits of using dynamic optimization principles in finding the optimum power dispatch schedule as well as the optimum operating point of the carbon capture process that results in minimum operational costs while the integrated system is exposed to an intermittent renewable source, a dynamic electricity demand profile, and time-of-day prices of electricity. This optimization framework is modular and can be easily modified and used for similar systems in many industries to optimize the operation of the system in response to the anticipated transient circumstances that occur in the system. In this work, two scenarios are considered for carbon capture plants. In the first scenario, carbon capture technologies operate without energy storage in an inflexible operation configuration. In the second scenario, energy storage is incorporated into the model that allow for flexible operation of the capture plant. The comparison results show that while both systems are able to meet the total electricity demand, the LTCC process has lower total operational costs than chemical absorption. Additionally, the low temperature carbon capture consumes less energy per unit of $\mathrm{CO}_{2}$ captured.

The remainder of this paper is divided into 5 Sections; in Section 2 integration of the coal-fired power plant with each of the carbon capture technologies is briefly 
reviewed. Section 3 discusses the common assumptions made in each system and the modeling and optimization frameworks used to describe each technology are also presented. Then, Section 4 presents the simulation results for both systems with and without energy storage. Finally, Section 5 provides a conclusion of the main achievements in this paper as well as a summary of the shortcomings of each model and directions for future work.

\section{Description of Carbon Capture Plants}

This section provides an overview of integration of the two capture technologies with a base power plant for inflexible and flexible operations.

\subsection{Low Temperature Carbon Capture}

Low temperature carbon capture separates carbon dioxide by cooling down the power plant flue gases to the desublimation temperature of $\mathrm{CO}_{2}$. Solid $\mathrm{CO}_{2}$ is then separated from the remaining flue gases by filtration and liquefied by using the heat available from other streams in the process. Once liquiefied, $\mathrm{CO}_{2}$ is pressurized and transported to the pipeline for other applications such as enhanced oil recovery and fertilizer production. The series of processes that the $\mathrm{CO}_{2}$-containing streams go through, as described above, are shown in Figure 1 as a box entitled as "LTCC process". More details about the LTCC process are available in 47, 48, 49]. The cooling medium for the LTCC process is provided by two refrigeration cycles (internal and

external). The internal refrigeration cycle uses $\mathrm{CF}_{4}$ as the refrigerant while liquefied natural gas (LNG) is used in the external cycle. A mixed refrigerant cycle is also utilized to produce LNG in the LNG/mixed refrigerant recuperator [50,51, 52]. 


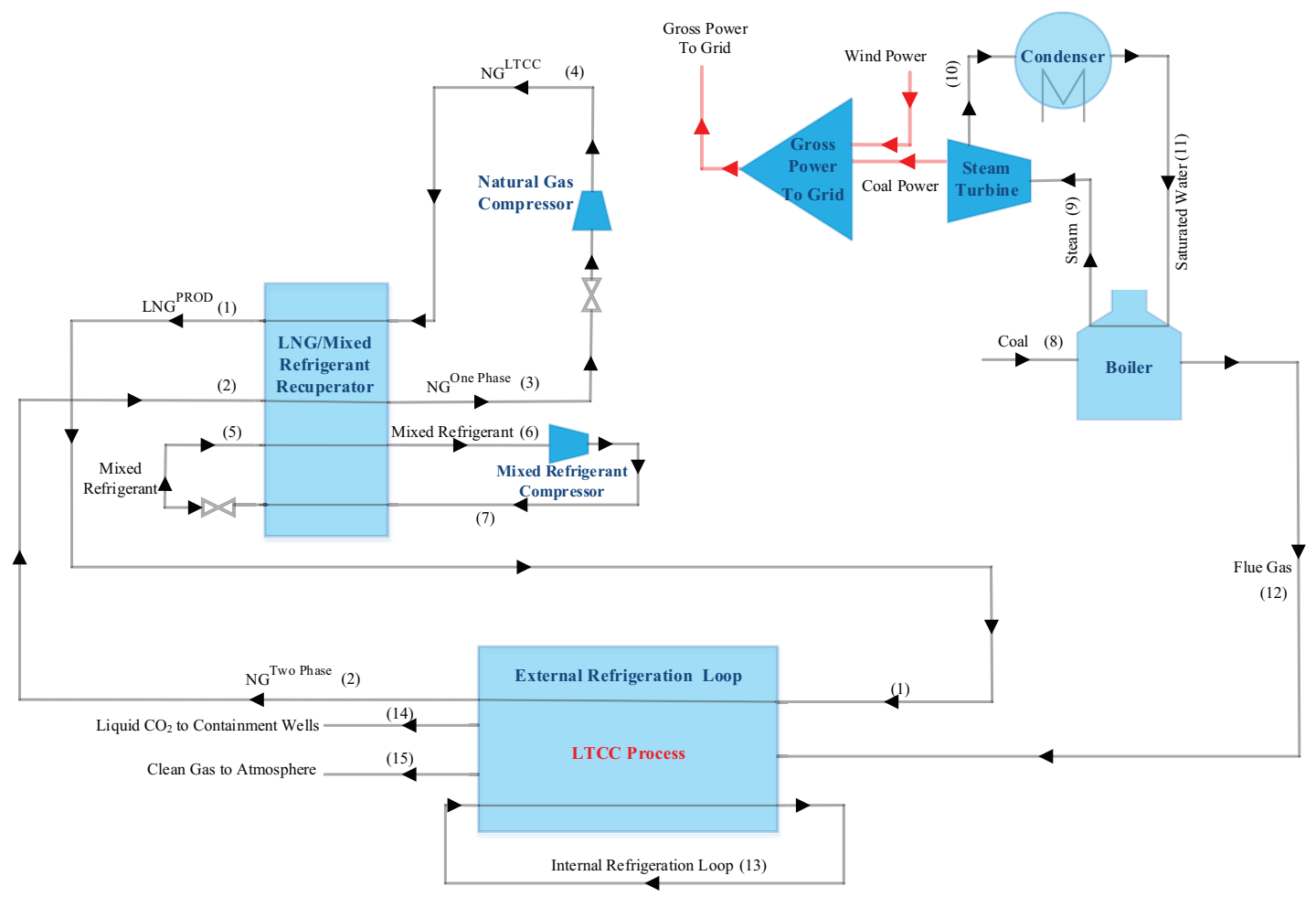

(a) Without energy storage

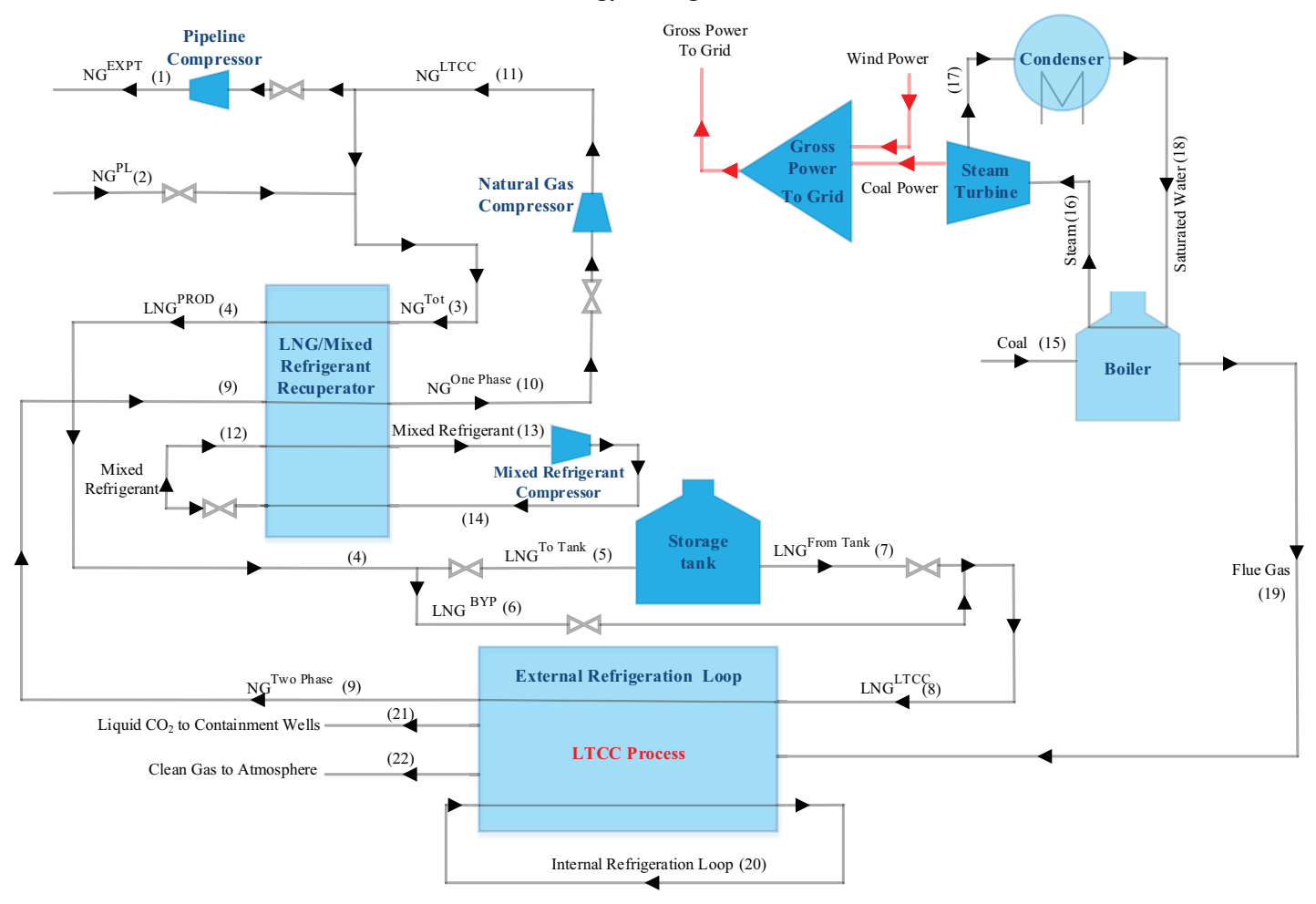

(b) With energy storage

Figure 1: Power plant integration with the LTCC system 
In the inflexible operation of the LTCC process, a constant amount of natural gas is circulated to the LNG production facility and the flow rate changes to meet the peak refrigerant demand. In the flexible scenario of the LTCC process, natural gas could be imported from the pipeline and the rate of LNG production can be adjusted according to the volatile electricity price and demand. This is possible because an insulated tank is utilized in the flexible scenario and LNG is produced in excess and stored in the tank during periods with low electricity prices. When electricity is more expensive, LNG is retrieved from the tank to meet the refrigerant demand of the LTCC process. A bypass stream is also used in the flexible scenario to continuously meet the LNG demand of the LTCC process, either partially or completely (according to the electricity price). It should also be noted that the LTCC process and LNG production facilities can operate separately from each other that is a direct result of energy storage. In both scenarios of the LTCC process, the electricity demand of the mixed refrigerant compressor is directly related to the rate of LNG production. Additionally, LNG vaporizes at the outlet of the capture plant in both scenarios and it produces a two-phase stream (95-97\% vapor fraction) [47, 48, 49]. This stream reaches ambient temperatures by transferring heat in the LNG/mixed refrigerant recuperator, followed by a pressurization step in the natural gas compressor. In the flexible scenario, a portion of the exiting gas from the natural gas compressor can be exported to a pipeline during peak hours for electiricity demand and prices. This permits a reduction in the parasitic electricity demand of the mixed refrigerant compressor during peak hours, resulting in a more stable power grid and reduced operational costs. To export natural gas from this system, the pressure should be increased in the pipeline compressor, as shown in Figure 1. It is also important to note that simultaneous import and export of natural gas is not a likely operational scenario. Because of the tight heat integration in the LTCC process and compression of the separated $\mathrm{CO}_{2}$ in liquid form, the LTCC process consumes lower energy than typical cryogenic processes [47. More information about the LTCC process is available in $47,53,6,54$. 


\subsection{Chemical Absorption}

In the chemical absorption system shown in Figure 2, the flue gases from the power plant are exposed to a lean solvent stream in an absorber column. Consequently, $\mathrm{CO}_{2}$ is absorbed in the solvent, MEA in this study, making it $\mathrm{CO}_{2}-$ rich. The rich solvent is then regenerated in a stripping column where steam is used to strip

$\mathrm{CO}_{2}$ from the rich solvent stream. After this mass transfer takes place, $\mathrm{CO}_{2}$ transfers to the steam and is finally separated from the steam in a condenser. The separated $\mathrm{CO}_{2}$ in this system is in the gas phase and should be pressurized in a compressor before it is transported from the integrated system. 


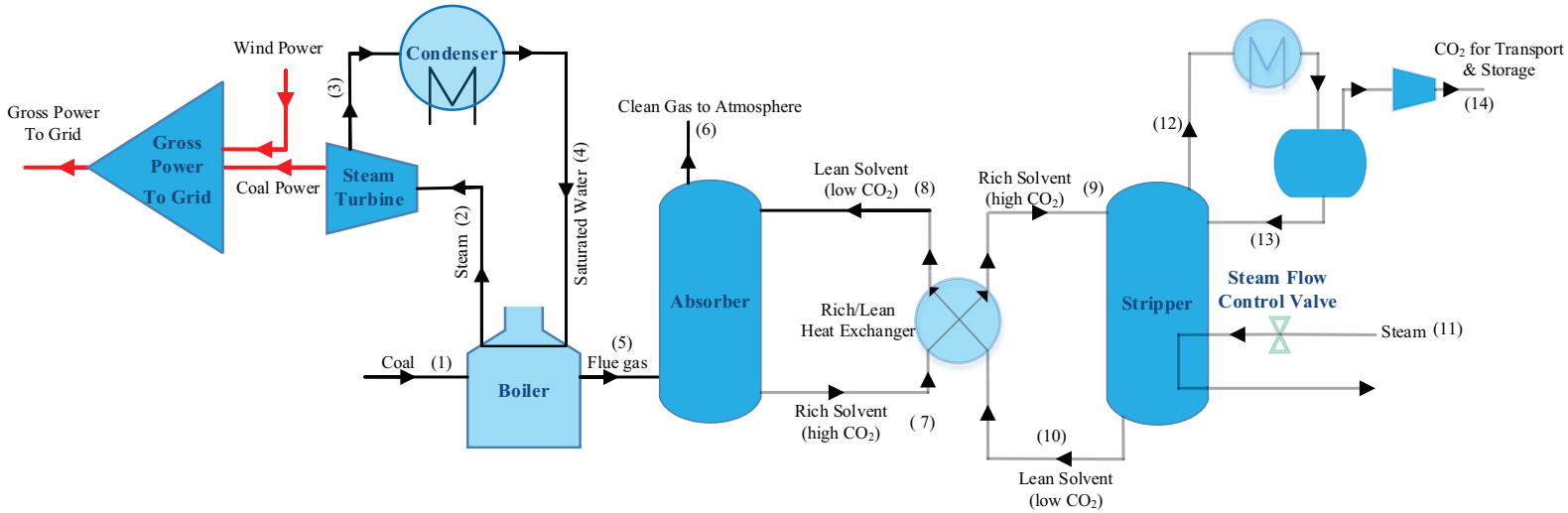

(a) Without energy storage

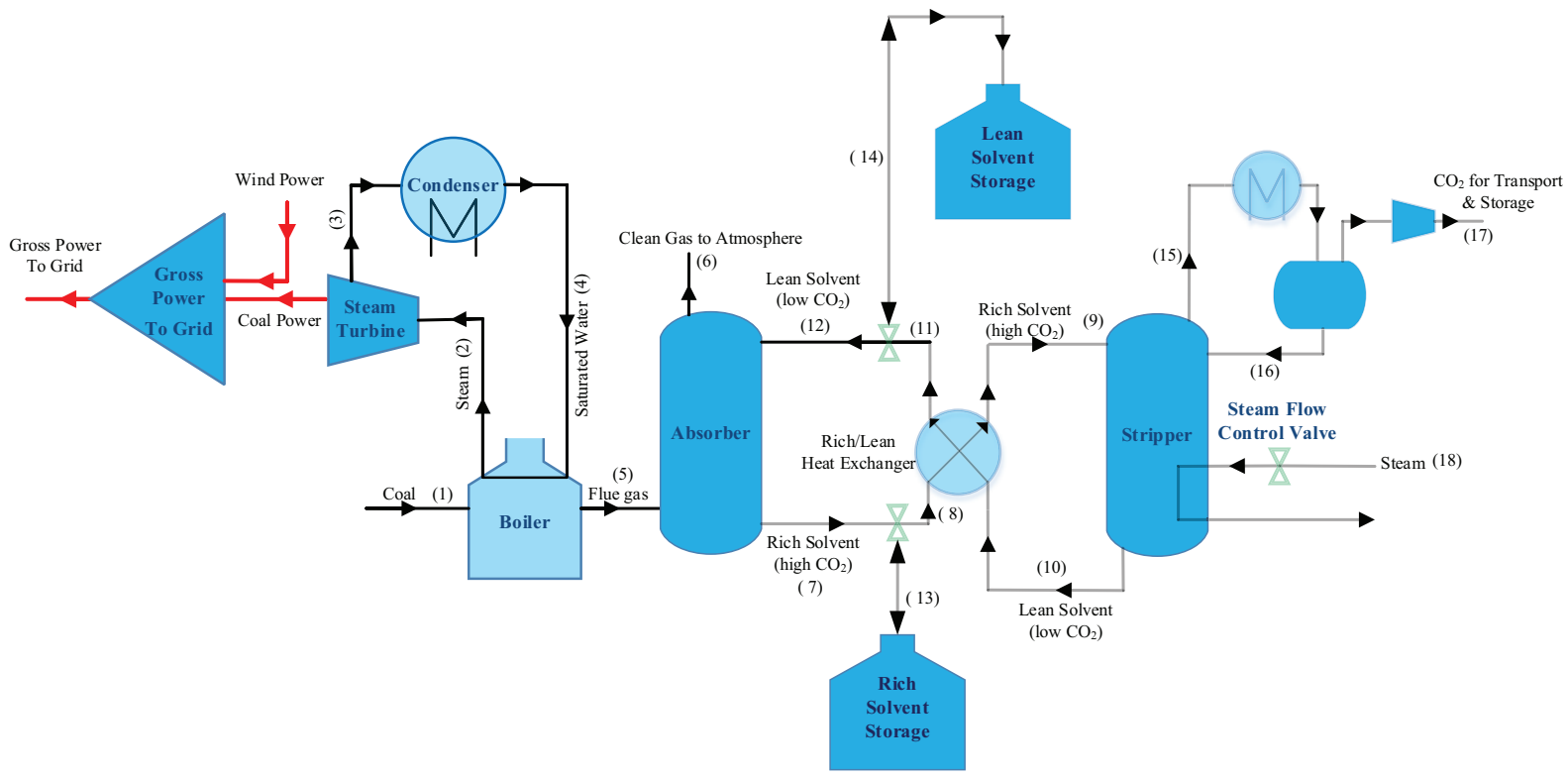

(b) With energy storage

Figure 2: Power plant integration with chemical absorption

In the inflexible operation of this capture scheme, rich solvent is regenerated at the same time that $\mathrm{CO}_{2}$ absorption process occurs. This results in continuous operation of the stripping and compression units. In the flexible scenario, however, rich solvent is directed to a storage tank during periods with expensive electricity. 
When the electricity price is sufficiently low, the rich solvent is retrieved from the storage tank and regenerated in the stripper. This permits the integrated system to reduce the parasitic demand of the stripping and compression units during peak hours for electricity demand and price, resulting in more stability in the power grid and reduced operational costs. In both inflexible and flexible operations, the regenerated solvent (lean solvent) from the bottom of the stripping column is circulated back into the absorption column. More information about this system is available in $18,19,20$.

\section{Model Description}

This section provides a brief overview of the modeling and optimization frameworks used to model each technology. Additionally, common assumptions made for each capture technology are presented. It should be noted that both technologies considered in this study have different configurations that vary largely between different research studies in regards to the characterizing performance indicators such as energy consumption or dynamic behavior. To overcome this issue, two of the more recent studies, with the process description mentioned in Section 2 are selected as the basis of comparison in this study. The dynamic performance of these systems as well as some of the economical aspects of each are compared, without necessarily generalizing the conclusions to other possible configurations of each technology. For this analysis, the model of chemical absorption is adopted from [18, 19, 21, 55], while the model of the low temperature carbon capture is previously developed by the authors in [53, 6]. In both models, some adjustments were needed to establish a similar basis for comparison. These adjustments provide consistency on the size of the storage tanks, maximum and minimum power outputs from the steam turbines, dynamic mass balance equations of the storage tanks, and the total operating costs of each system. Additionally, the electricity demands associated with a selective catalytic reaction (SCR) and a flue gas desulfurization (FGD) unit that were not taken into account in the models referenced above are also included in the current study. These modifications are explained in further detail in the sub- 
sequent paragraphs.

The goal in this work is to minimize the total operational costs of the integrated system while enough power is produced to match the total demand. The total electricity demand in this analysis includes the demand associated with the residential users as well as that of the capture process. The objective functions representing the total costs in the LTCC and chemical absorption systems are shown in Equations 1 and 2 respectively. The terms used in these equations are also defined in Table 1 To minimize the mismatch between power demand and production, an additional term is also added in both equations that represents the cost associated with power imbalances. Imbalance cost is assumed to be the product of power imbalance and a penalty factor. In both systems, minimizing the cost associated with power imbalances is prioritized over minimizing the actual operational cost of the integrated systems. To achieve this objective, the penalty factor is adjusted to ensure that power imbalances are minimized first.

$$
\begin{gathered}
\text { Oper.Cost }{ }^{L T C C}=\sum\left(C^{\text {Cap.Energy }}+C^{\text {Fuel }}+C^{N G, N e t}\right. \\
\left.+C^{C \mathrm{O}_{2} \text { Emission }}+C^{O \& M, b}+C^{O \& M, L T C C}+C^{\text {imbal }}\right) T \\
\text { Oper.Cost } \\
\left.+C^{\text {Chelv. }}+C^{\text {Caus. }}+C^{\text {Waste }}+C^{\text {Wat. }}+C^{\text {Trans. }}+C^{\text {Cap.Ramp }}+C^{\text {imbal }}\right) T
\end{gathered}
$$

To calculate the terms of Equations 1 and 2, additional information is needed. This includes base information for the power plant such as coal properties, fuel price, heat and $\mathrm{CO}_{2}$ emission rates, $\mathrm{CO}_{2}$ emission price, and operating and maintenance costs. Additionally, base information for each capture technology such as energy demand, solvent and refrigerant demands, operating and maintenance costs, and other miscellaneous data associated with the chemical absorption system are required. This information is provided in detail in [6, 55 and summarized in Table 2

While most coal-fired power plants operate on a relatively constant basis, the gross power output from both integrated systems is assumed to vary between 650 
Table 1: Nomenclature for Equations 1 and 2

\begin{tabular}{ll}
\hline Variable & Description \\
\hline Oper.Cost ${ }^{\text {LTCC }}$ & Total Operating cost of the LTCC system \\
\hline Oper.Cost ${ }_{\text {Chem.Abs. }}$ & Total Operating cost of the chemical absorption system \\
\hline$C^{\text {Cap.Energy }}$ & Energy cost of the capture process \\
\hline$C^{\text {Fuel }}$ & Fuel cost \\
\hline$C^{\text {NG,Net }}$ & Cost of net natural gas imported to the LTCC system \\
\hline$C^{\text {CO } O_{2} \text { Emission }}$ & Penalty cost of CO 2 emission \\
\hline$C^{\text {O\&M,b }}$ & Operating and maintenance costs of the base power plant \\
\hline$C^{\text {O\&M,LTCC }}$ & Operating and maintenance costs of the LTCC capture \\
\hline$C^{\text {imbal }}$ & Power imbalance cost \\
\hline$T$ & Time increment \\
\hline$C^{\text {Solv. }}$ & Solvent cost of the chemical absorption \\
\hline$C^{\text {Caus. }}$ & Caustic cost of the chemical absorption \\
\hline$C^{\text {Waste }}$ & Waste cost of the chemical absorption \\
\hline$C^{\text {Wat. }}$ & Water cost of the chemical absorption \\
\hline$C^{\text {Trans. }}$ & Transportation cost of the chemical absorption \\
\hline$C^{\text {Cap.Ramp }}$ & Ramping cost of the chemical absorption \\
\hline
\end{tabular}

and $2350 \mathrm{MW}$. This is because the residential electricity demand assumed in this study varies significantly. Since power production from coal is the only source in this study that can be adjusted to meet this demand, it is necessary to assume that the coal-fired power plant is able to follow the demand. However, the rate of change of power output is limited to $300 \mathrm{MW}$ per hour to account for the slow response of boilers in responding to rapid changes in the electricity demand. These assumptions could be easily modified when more capable load-following generation units such as gas power plants are included in the analysis. Additionally, it is assumed that a cluster of boilers is used to produce power as much as $2350 \mathrm{MW}$. It is important to note that the efficiency of power generation from the combustion of coal, without taking into account the energy losses associated with carbon capture, is $31.55 \%$ in 
both systems. The rate of $\mathrm{CO}_{2}$ capture is also assumed to be $90 \%$ for both technologies.

In the chemical absorption system, the capture plant is inherently and heavily integrated with the power plant and it struggles with load following. The LTCC process, however, primarily consists of compressors and heat exchangers [56] and it does not integrate much heat with the power plant. Thus, it is possible to vary the LTCC demand independently from the power plant output. Consequently, ramping rates of the absorber and stripper are constrained in the chemical absorption system while the LTCC demand can vary with no significant limitation. The costs associated with ramping the chemical absorption process, $C^{\text {Cap.Ramp in Equation } 2 \text { are }}$ proportional to the magnitude of change in absorber and stripper load. The constant of proportionality is the product of the time interval length, expected average annual electricity price, maximum gross power output, and ratio of the efficiency point penalty associated with a $100 \%$ ramp to the base plant efficiency [55].

To transport $\mathrm{CO}_{2}$ via pipeline, it is necessary to pressurize it to the pipeline pressure ( $125-150$ bar ) in both systems. It should, however, be noted that the electricity demand value reported for the LTCC process in [47] is based on pressurizing $\mathrm{CO}_{2}$ to $99.95 \mathrm{bar}$, while the temperature of $\mathrm{CO}_{2}$ delivered by the process is $292.69 \mathrm{~K}$. The near ambient temperature of the LTCC process is because of the tight heat integration that exists in the process. At these conditions, liquid $\mathrm{CO}_{2}$ is delivered by the LTCC process. In the chemical absorption system, it is assumed that $\mathrm{CO}_{2}$ is pressurized to 150 bar while the compressor outlet temperature is not reported in [55]. However, there are several indications in this study that $\mathrm{CO}_{2}$ is transported in gas form.

To investigate further, a series of simulations is implemented, using a commercial process simulator, for a pure $\mathrm{CO}_{2}$ stream. First, the $\mathrm{CO}_{2}$ stream from the LTCC plant is pressurized to $150 \mathrm{bar}$ to ensure that it has a similar outlet pressure as the chemical absorption system. The $\mathrm{CO}_{2}$ exiting the pump at 150 bar in the LTCC case is liquid at a temperature of $299.1 \mathrm{~K}$, while the pump shaft work is equivalent to $1.82 \mathrm{e}-06 \mathrm{MWh} / \mathrm{kg}$ at an adiabatic pump efficiency of $90 \%$. This is the shaft work to pressurize liquid $\mathrm{CO}_{2}$ from 99.95 bar to 150 bar but $\mathrm{CO}_{2}$ pressurization work from 
Table 2: Model values

\begin{tabular}{|c|c|}
\hline Variable description & Value \\
\hline Coal heating value $(M M B T U / \mathrm{kg})$ & 0.0184 \\
\hline Coal price $(\$ / M M B T U)$ & 2.25 \\
\hline Natural gas price ( $\$ /$ thousand cubic feet) & 4.51 \\
\hline Solvent price $(\$ / k g)$ & 2.52 \\
\hline Base plant heat rate $(M M B T U / M W h)$ & 10.8184 \\
\hline Base plant $\mathrm{CO}_{2}$ emissions rate $\left(k g \mathrm{CO}_{2} / M W h\right)$ & 851.23 \\
\hline LTCC overall energy demand ( $M J / k g \mathrm{CO}_{2}$ captured) & 0.7369 \\
\hline Chemical absorption overall energy demand ( $M J / k g \mathrm{CO}_{2}$ captured) & 0.9684 \\
\hline LNG demand ( $k g / k g \mathrm{CO}_{2}$ captured) & 0.856 \\
\hline Solvent consumption (and makeup) ( $\left.\mathrm{kg} \mathrm{MEA} / \mathrm{kg} \mathrm{CO} \mathrm{CO}_{2}\right)$ & 0.0015 \\
\hline Solvent consumption (from thermal degradation) $(\mathrm{kg} \mathrm{MEA} / \mathrm{kg} \mathrm{CO}$ ) & 0.0001 \\
\hline $\mathrm{CO}_{2}$ emission price $\left(\$ / \mathrm{kg} \mathrm{CO} \mathrm{CO}_{2}\right)$ & 0.050 \\
\hline Operating and maintenance cost for the power plant $(\$ / M W h)$ & 15.1 \\
\hline Operating and maintenance cost for the LTCC $(\$ / M W h)$ & 2.4 \\
\hline Operating and maintenance cost for the chemical absorption $(\$ / M W h)$ & 5.84 \\
\hline Caustic consumption in reclaimer $\left(\mathrm{kg} \mathrm{NaOH} / \mathrm{kg} \mathrm{CO} \mathrm{CO}_{2}\right)$ & 0.000075 \\
\hline Caustic cost $(\$ / k g \mathrm{NaOH})$ & 0.5 \\
\hline Waste disposal cost ( $\$ / k g$ Waste) & 0.2188 \\
\hline Water price $\left(\$ / m^{3}\right)$ & 0.29 \\
\hline
\end{tabular}

$5.99 \mathrm{bar}$ (i.e. the condition before pressurization of $\mathrm{CO}_{2}$ to $99.95 \mathrm{bar}$ ) to $150 \mathrm{bar}$ also results in 3.825e-06 MWh/ $\mathrm{kg}$, resulting in a total demand of 5.64e-06 $\mathrm{MWh} / \mathrm{kg}$ to pressurize $\mathrm{CO}_{2}$ from 5.99 bar to 150 bar .

A simulation is also implemented to further investigate the chemical absorption system. The temperature and pressure of $\mathrm{CO}_{2}$ entering the compressor (exiting stream from the stripper column) are not reported in [55]. The inlet conditions of the $\mathrm{CO}_{2}$ compressor are, therefore, chosen based on similar studies such as those reported in [57]. These values are assumed to be 1.6 bar and $294.15 \mathrm{~K}$, resulting in 
gaseous $\mathrm{CO}_{2}$. The outlet pressure of the compressor in [57] is $150 \mathrm{bar}$, consistent with that of [55], resulting in a simulated outlet temperature of $760.5 \mathrm{~K}$. The compressor demand associated with increasing the pressure from $1.6 \mathrm{bar}$ to $150 \mathrm{bar}$ is 1.27e-04 MWh $/ \mathrm{kg}$ at a compressor adiabatic efficiency of $90 \%$. The $\mathrm{CO}_{2}$ pressurization demand is, therefore, significantly higher than that of the LTCC process. Because the $\mathrm{CO}_{2}$ compressor outlet temperature is high, cooling of $\mathrm{CO}_{2}$ is very likely to occur in a real operation while avoiding $\mathrm{CO}_{2}$ liquefaction due to the high operational costs. As mentioned previously, the compressor outlet temperature is not reported in [55]; thus, different outlet temperatures are considered for the $\mathrm{CO}_{2}$ exiting the compressor, starting with that reported in [57] (308.15 K). Cooling the high pressure $\mathrm{CO}_{2}$ to $308.15 \mathrm{~K}$ results in a liquid stream while any temperature higher than $325.5 \mathrm{~K}$ results in gaseous $\mathrm{CO}_{2}$. Because $\mathrm{CO}_{2}$ liquefaction is unlikely to occur in reality and due to the indications that are available in [55] for the transportation of $\mathrm{CO}_{2}$ in gas form, it is anticipated that the outlet temperature of $\mathrm{CO}_{2}$ exiting the compressor is approximately $325.5 \mathrm{~K}$ (or higher). This assumption ensures that all the electricity demand numbers used in this study for the chemical absorption system are consistent with those suggested in [55]. At these conditions, $\mathrm{CO}_{2}$ is delivered in the gas form by the chemical absorption process.

In this work, a cost of $1.06 \mathrm{c} /(\mathrm{kg} \mathrm{CO} 2)$ is also assumed for the transportation of $\mathrm{CO}_{2}$ in the chemical absorption system while this cost is assumed negligible in the LTCC system. This is because the transportation costs involve primarily overcoming pressure drop in the pipeline and other transportation-related issues. Noting that liquid form of $\mathrm{CO}_{2}$, delivered by the LTCC process, has much lower pressure drop in the pipeline than that of the gas form that is delivered by the chemical absorption, this assumption is reasonable.

Additionally, both capture systems consider an SCR and an FGD unit before the $\mathrm{CO}_{2}$ capture process. Consequently, the overall energy demands of the SCR and FGD units as well as the $\mathrm{CO}_{2}$ capture and pressurization units add up to 0.7369 and $0.9684 \mathrm{MJ}$ per $\mathrm{kg} \mathrm{CO} 2$ captured for the LTCC and chemical absorption, respectively [18 55, 48, 47, 58. A breakdown of these numbers, in correspondence to the components shown in Figures 1 and 2 is provided in Table 3 . The lower energy demand of 
Table 3: A breakdown of the major energy-consuming components of the carbon capture processes,

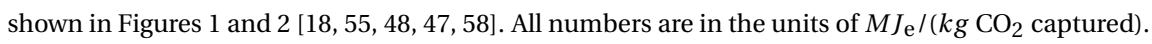

\begin{tabular}{lcc}
\hline & LTCC & $\begin{array}{c}\text { Chemical } \\
\text { absorption }\end{array}$ \\
\hline $\begin{array}{l}\text { Work of compression for natural } \\
\text { gas compressor }\end{array}$ & 0.1657 & - \\
\hline $\begin{array}{l}\text { Work of compression for mixed } \\
\text { refrigerant compressor }\end{array}$ & 0.1818 & - \\
\hline $\begin{array}{l}\text { Electricity demand of all auxiliary } \\
\text { units for treatment of the flue gas } \\
\text { (including SCR and FGD) }\end{array}$ & 0.3894 & - \\
\hline Absorption electricity demand & - & 0.1065 \\
\hline $\begin{array}{l}\text { Stripping/compression electric- } \\
\text { ity demand }\end{array}$ & - & 0.8619 \\
\hline SCR and FGD electricity demand & - & $1.5 \mathrm{e}-06$ \\
\hline
\end{tabular}

the LTCC process is mainly due to the tight heat integration of the process as well as compression of the separated $\mathrm{CO}_{2}$ in liquid form, as discussed above. These numbers are used in this study to calculate $C^{\text {Cap.Energy }}$ in Equation 22 However, it should be emphasized that the absolute baseline numbers provided in Table 2 for both the LTCC and chemical absorption are uncertain and they are pending for further fullscale demonstrations for each technology.

The simulation time spans 8 days with hourly data for electricity demand from a residential area in San Diego, California [59]. Hourly data is also used for the electricity price and wind power production [60 61]. The results presented in Section 4 are, however, for the four middle days to ensure that results are not affected by boundary conditions. The input data used for residential demand, electricity price, and wind power are for the period between September 13, 2014 and September 20, 2014 that represent the peak residential electricity demand of the year in the area. The trends of these inputs are shown in Figure 3

A tank size of 8 million $k g$ was obtained to provide enough capacity for 2-3 days 


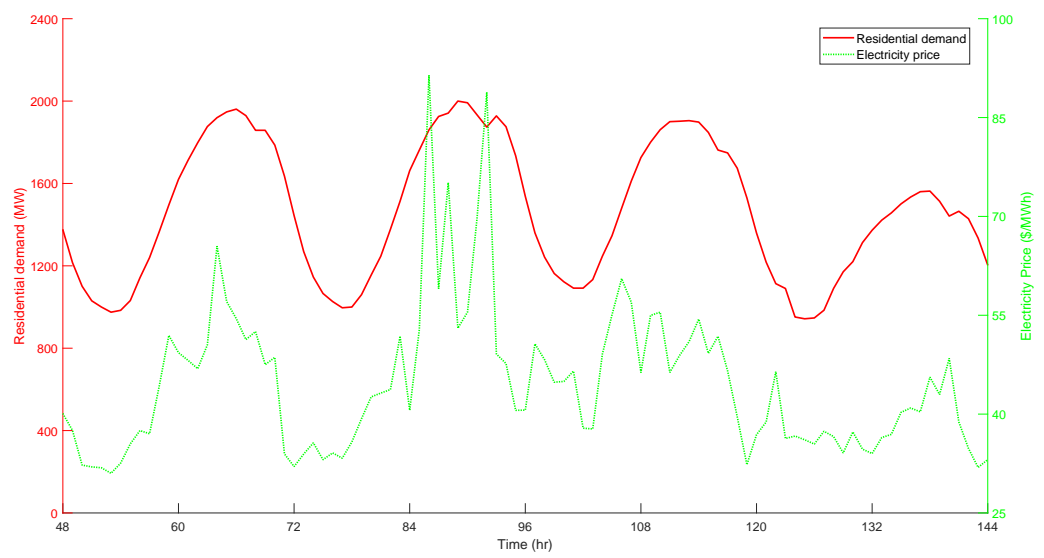

(a) Residential demand vs. electricity price

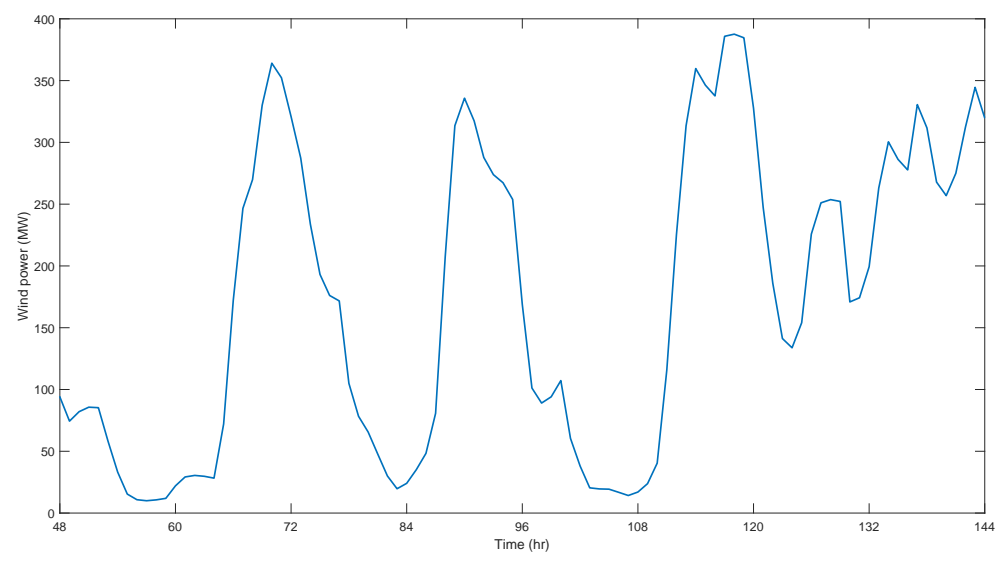

(b) Wind power

Figure 3: Actual electricity demand, average electricity price, and wind power data for southern California, USA, for the period between September 13, 2014 and September 20, 2014 [59 60 . 
of storage of LNG in the energy-storing case of the LTCC process for the assumed electricity demand profile [53]. This corresponds to 27,529 $\mathrm{m}^{3}$ of LNG at cryogenic conditions of the tank. While this capacity should be optimized with consideration of capital costs in the future work, it is an appropriate assumption for the purpose of this comparison. To have a similar basis for the chemical absorption system, two cases could be considered: 1) when the tank should hold 27,529 $\mathrm{m}^{3}$ of $\mathrm{CO}_{2}$, despite the fact that the tank conditions are different from the LTCC case (similar volumetric capacity for both systems) 2) when the tank should hold 8 million $\mathrm{kg}$ of $\mathrm{CO}_{2}$ at the conditions of the tank in the chemical absorption system (similar mass capacity for both systems). While results are not shown for the first case (similar volumetric capacity), it was observed that the storage capacity of $27,529 \mathrm{~m}^{3}$ for the chemical absorption system is very small and the flexibility of operation intended for the entire system is negligible (i.e., results for this storage capacity is similar to a case without energy storage). Thus, only results for the similar mass capacity of the tanks in both capture technologies are shown in Section 4 To calculate the volumetric storage capacity of the chemical absorption tank, corresponding to 8 million $\mathrm{kg}$ of $\mathrm{CO}_{2}$, the following equation from [55] is utilized that relates the tank size to solvent properties:

$$
\text { Tank }{ }^{\text {Chem.Abs. }}=(\varphi \omega \rho / \Omega)\left(M^{C O_{2}} / M^{\text {Solv. }}\right)
$$

where Tank $k^{\text {Chem.Abs. }}, \varphi, \omega, \rho, \Omega, M^{C O_{2}}, M^{\text {Solv. }}$ represent the volumetric $\mathrm{CO}_{2}$ storage capacity $(\mathrm{kg})$, solvent storage tank $\left(\mathrm{m}^{3}\right)$, solvent weight fraction, solution density $\left(\mathrm{kg} / \mathrm{m}^{3}\right)$, design $\mathrm{CO}_{2}$ carrying capacity ( $\mathrm{kmol}$ solvent $/ \mathrm{kmol} \mathrm{CO}_{2}$ ), and molecular weights of $\mathrm{CO}_{2}$ and solvent $(\mathrm{kg} / \mathrm{kmol})$, respectively. The values used for these parameters are summarized in Table 4 . Using the input values of Table 4 for a mass capacity of $8 \mathrm{MM} \mathrm{kg}$ of $\mathrm{CO}_{2}$ results in a solvent storage capacity of 290,840 $\mathrm{m}^{3}$ for the chemical absorption system. It is important to emphasize that the volumetric tank capacity for the LTCC system is still 27,529 $\mathrm{m}^{3}$.

The dynamic mass balance of $\mathrm{LNG}$ and $\mathrm{CO}_{2}$ storage are also presented by Equa- 
Table 4: Parameters for Equation 3

\begin{tabular}{|c|c|}
\hline Variable description & Value \\
\hline Tank ${ }^{\text {Chem.Abs. }}(\mathrm{kg})$ & $8 \mathrm{MM}$ \\
\hline$\omega$ & 0.3 \\
\hline$\rho\left(k g / m^{3}\right)$ & 1,060 \\
\hline$\Omega\left(\mathrm{kmol}\right.$ solvent $\left./ \mathrm{kmol} \mathrm{CO}_{2}\right)$ & 8.33 \\
\hline$M^{\mathrm{CO}_{2}}(\mathrm{~kg} / \mathrm{kmol})$ & 44.01 \\
\hline$M^{\text {Solv. }}(\mathrm{kg} / \mathrm{kmol})$ & 61.08 \\
\hline
\end{tabular}

tions 4 and 5 respectively.

$$
\begin{gathered}
\frac{d\left(L N G^{\text {Tank }}\right)}{d t}=L N G^{\text {To Tank }}-L N G^{\text {From Tank }} \\
\frac{d\left(\mathrm{CO}_{2}\right)}{d t}=\mathrm{CO}_{2}{ }^{\text {Captured }}-\mathrm{CO}_{2} \text { Stripped }
\end{gathered}
$$

The models developed for both systems involve nonlinear terms. While finding a global minimum cost for each model is not the objective of this work, appropriate initial values are obtained for each model, based on the guidelines provided in similar works 62, 63. Finding appropriate initial conditions also help in reducing the computational time. The models of both hybrid systems are programmed in GAMS modeling language [64]. To achieve minimum cost in each case, decision variables are optimized by using a nonlinear optimization solver (KNITRO in this study) 65, 66, 67, 68, 69, 70, 71. The decision variables used in both cases are summarized in Table 5 More details about the equations used in each system are available in [6, 55.

\section{Simulation Results}

This section provides the comparison between the low temperature and chemical absorption capture schemes with and without energy storage. 
Table 5: Decision variables for each model

\begin{tabular}{cc}
\hline LTCC & Chemical Absorption \\
\hline Base plant power output & Base plant power output \\
\hline Power imbalance & Power imbalance \\
\hline Natural gas imported & Stripped $\mathrm{CO}_{2}$ \\
\hline Natural gas exported & \\
\hline LNG to tank & \\
\hline LNG from tank & \\
\hline
\end{tabular}

\subsection{Results for Scenario Without Energy Storage}

As mentioned in Section 3. meeting the total electricity demand is given a higher priority than minimizing the total operating cost. Simulation results shown in Figures $4 \mathrm{a}$ and $4 \mathrm{~b}$ demonstrate that in both systems, the total electricity demand is supplied from a combination of coal combustion and available wind power. In both systems, the model is formulated such that the available wind power, also shown in Figures $4 \mathrm{a}$ and $4 \mathrm{~b}$, is utilized first in meeting the electricity demand. This results in $100 \%$ utilization of available wind power. In the LTCC scheme, wind power provides $1.6436 \mathrm{e}+04 \mathrm{MWh}$ of energy over the simulation time while the total electricity demand is $1.6501 \mathrm{e}+05 \mathrm{MWh}$. This corresponds to $9.96 \%$ contribution of the wind power in meeting the total electricity demand of the integrated system. In the chemical absorption system, the total power production from wind is the same as the LTCC system because it is an input to both models. The total electricity demand of the chemical absorption system is, however, $1.7296 \mathrm{e}+05 M W h$, resulting in supplying $9.5 \%$ of the total power demand from wind. It should also be noted that the total power production from coal, over the simulation time, in the LTCC scheme is $5.06 \%$ less than that of chemical absorption. Figures $5 \mathrm{a}$ and $5 \mathrm{~b}$ present the coal power generation and capture process energy demand (also shown in Figures $4 \mathrm{a}$ and $4 \mathrm{~b}$ against the electricity price trend. It is obtained from Figure $5 \mathrm{~b}$ that the LTCC process requires $24.52 \%$ less energy than the chemical absorption over the simulation time. Taking into account the amount of $\mathrm{CO}_{2}$ captured in each system, 
it is observed that the LTCC process requires $20.5 \%$ less energy per $\mathrm{kg}$ of $\mathrm{CO}_{2}$ captured. The lower energy demand of the LTCC process (as well as lower electricity generation from coal) is attributed to the tight energy integration that exists in the process as well as compression of the captured $\mathrm{CO}_{2}$ in liquid form. For the scenario without energy storage, it is seen in Figure $5 \mathrm{~b}$ that the trends of energy demand of both capture systems correspond to a peak in electricity price; i.e., when electricity price is at a maximum, the total energy demand associated with the capture processes as well as all the components adding up to the total energy demand (shown in $6 \mathrm{a}$ and $6 \mathrm{~b}$ are also at a maximum. This results in increased operational costs of the integrated system. It can also cause instability in the power grid. This is because the peak of electricity price typically corresponds to a peak in residential electricity demand in the grid, as also seen in Figures 4 and 5 Additional electricity load on the power grid from carbon capture systems can lead to instability in the power grid. A comparison between the major components of the total electricity demand of each capture technology, as presented in Figures 1 and 2 is also provided in Table 6 for three levels of gross power output. 


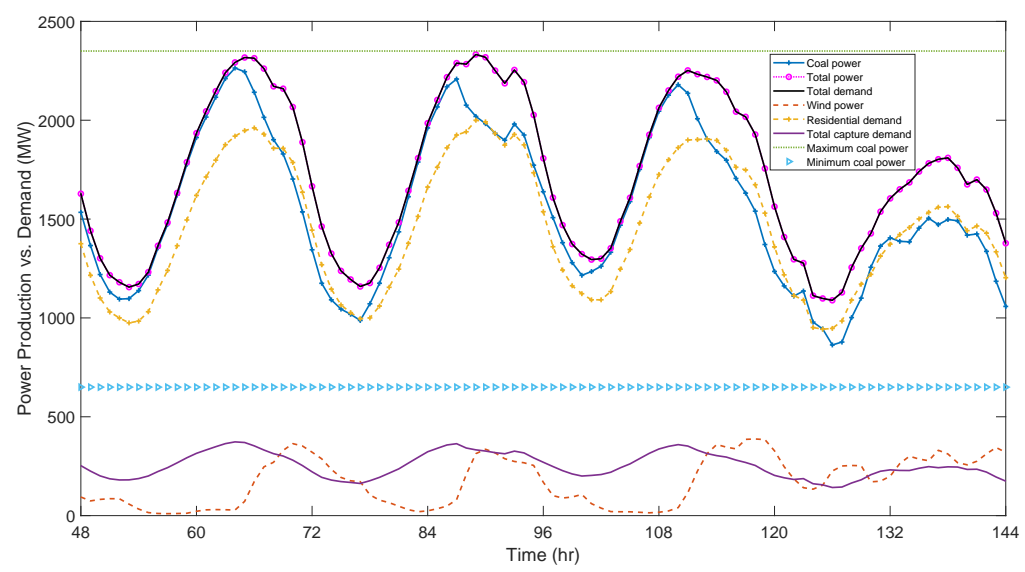

(a) Low temperature carbon capture

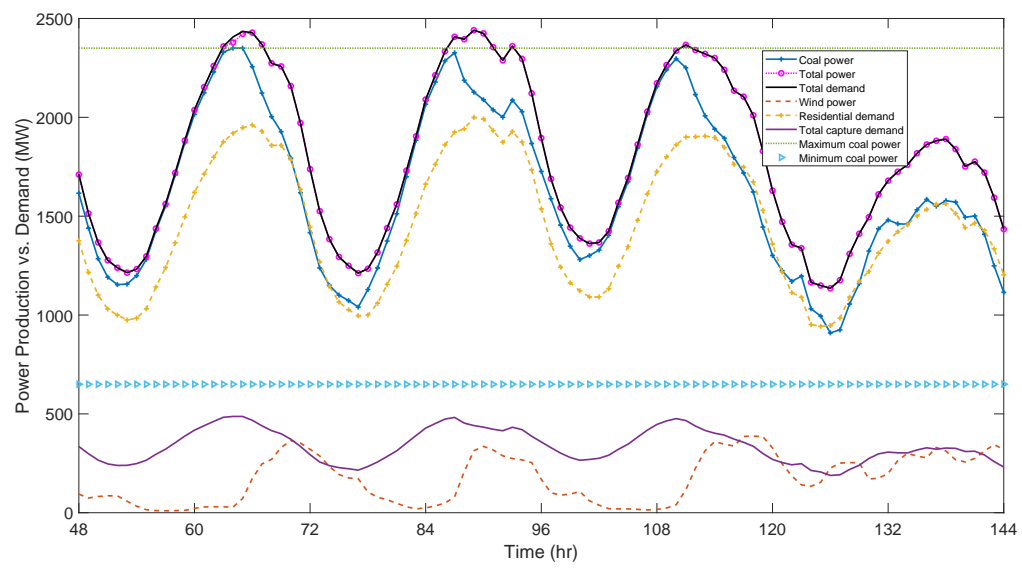

(b) Chemical absorption

Figure 4: Power vs. demand for scenario without energy storage 


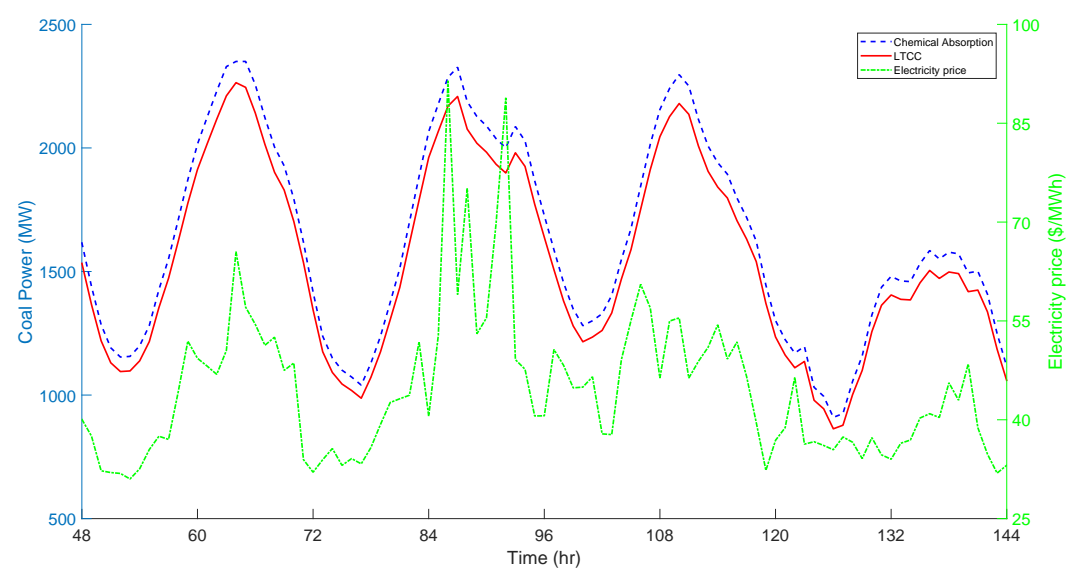

(a) Power production from coal

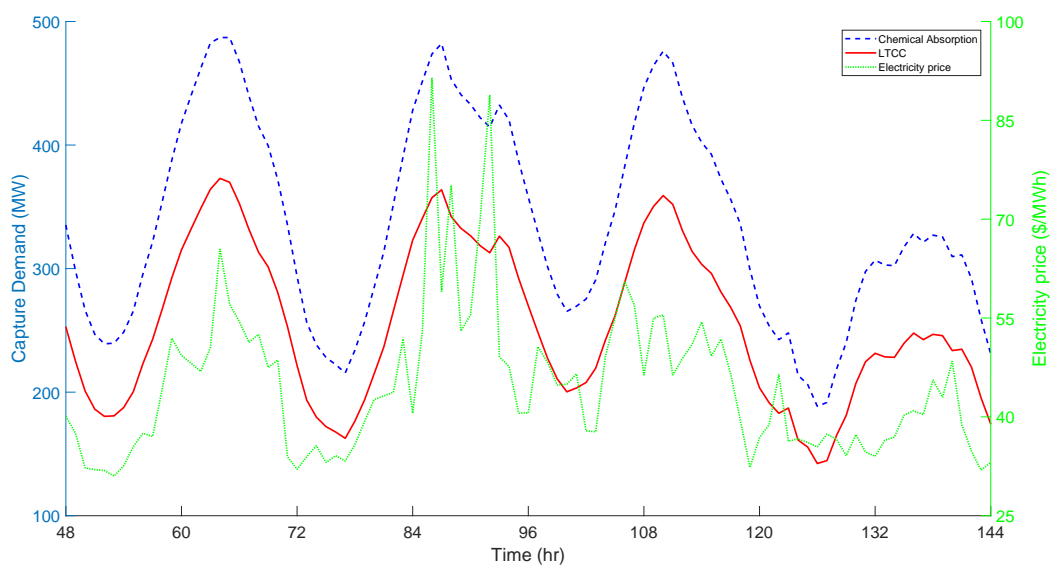

(b) Capture process overall energy demand

Figure 5: Comparison between coal power production and capture process overall energy demand for scenario without energy storage 


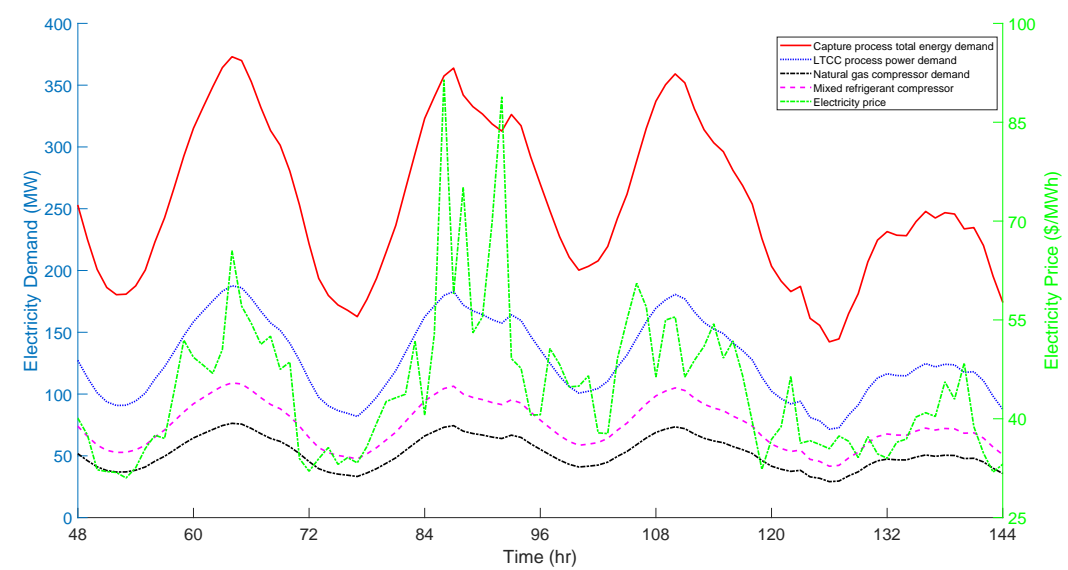

(a) Low temperature carbon capture

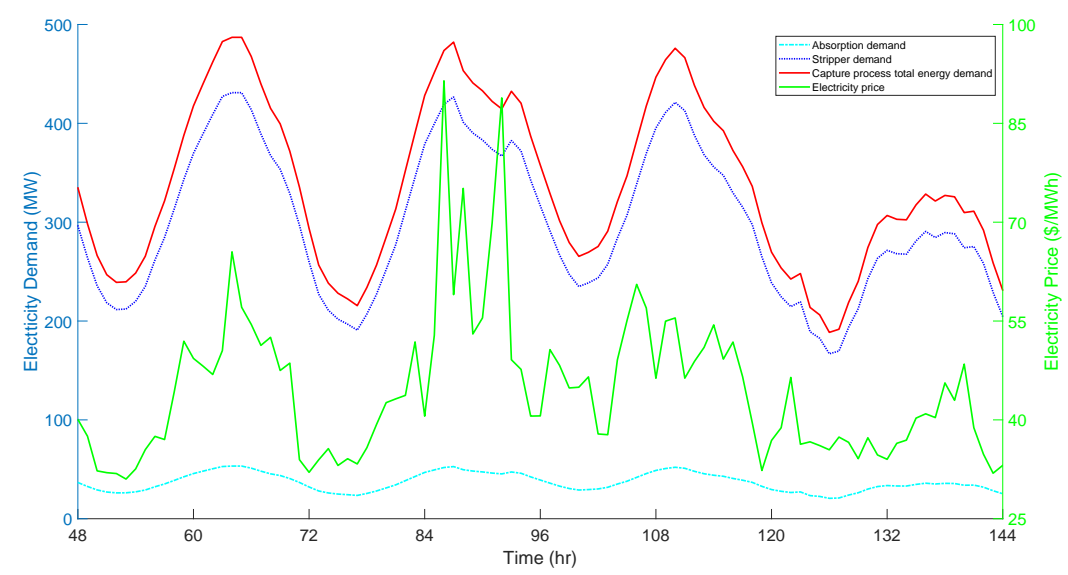

(b) Chemical absorption

Figure 6: Components of overall electricity demand of the capture processes for scenario without energy storage

In this scenario, the total operating costs associated with the low temperature carbon capture is $9.14 \%$ less than the chemical absorption system over the simulation time. Taking into account the total captured $\mathrm{CO}_{2}$ over the simulation time, it is observed that the total operating costs per $\mathrm{kg}$ of $\mathrm{CO}_{2}$ captured for the LTCC is $4.3 \%$ less than chemical absorption process. Table 8 provides a summary of the results for 
Table 6: A comparison between electricity demand $(M W)$ of major components of each carbon capture technology without energy storage at three levels of gross power output. Abbreviations are defined as NG: natural gas, MR: mixed refrigerant, Abs: absorption, Str: stripping, and Comp: compression

\begin{tabular}{|c|c|c|c|c|c|c|}
\hline \multirow{2}{*}{} & \multirow{2}{*}{ Gross power } & \multicolumn{2}{|c|}{ Low temperature carbon capture } & \multicolumn{2}{c|}{ Chemical absorption } \\
\cline { 3 - 7 } & & NG Comp. & MR Comp. & LTCC process & Abs. & Str./Comp. \\
\hline High load & 2264.2 & 76.3 & 109 & 187.6 & 51.3 & 415.4 \\
Intermediate load & 1472.8 & 49.6 & 70.9 & 122 & 32.3 & 261.7 \\
Low load & 909.7 & 30.7 & 43.8 & 75.4 & 28 & 227.1 \\
\hline
\end{tabular}

both capture technologies without energy storage.

\subsection{Results for Scenario With Energy Storage}

This section provides the comparison for when energy storage associated with each capture technology is considered. Similar to the scenario without energy storage, the primary objective is to meet the total energy demand. As shown in Figures $7 \mathrm{a}$ and $7 \mathrm{~b}$, both systems are able to meet the overall electricity demand, using a combination of coal and wind power. The model of the energy-storing case is also formulated such that the available wind power is utilized first in meeting the electricity demand while coal power is generated to meet the remaining electricity demand. The total power supply by wind for both systems over the simulation time are similar to the case without energy storage $(1.6436 \mathrm{e}+04 \mathrm{MWh})$. The total power demands of the integrated systems of the LTCC and chemical absorption are, however, $1.6072 \mathrm{e}+05$ and $1.7289 \mathrm{e}+05 \mathrm{MWh}$, respectively. This corresponds to 10.23 and $9.51 \%$ contribution of wind power in meeting the total electricity demand of the integrated system over the simulation time. For this scenario, it is also observed that the total power generated from coal in the LTCC process over four days of simulation time is $7.78 \%$ less than that of chemical absorption. The trend of power production from coal against the electricity price is also shown in Figure $8 \mathrm{a}$ 


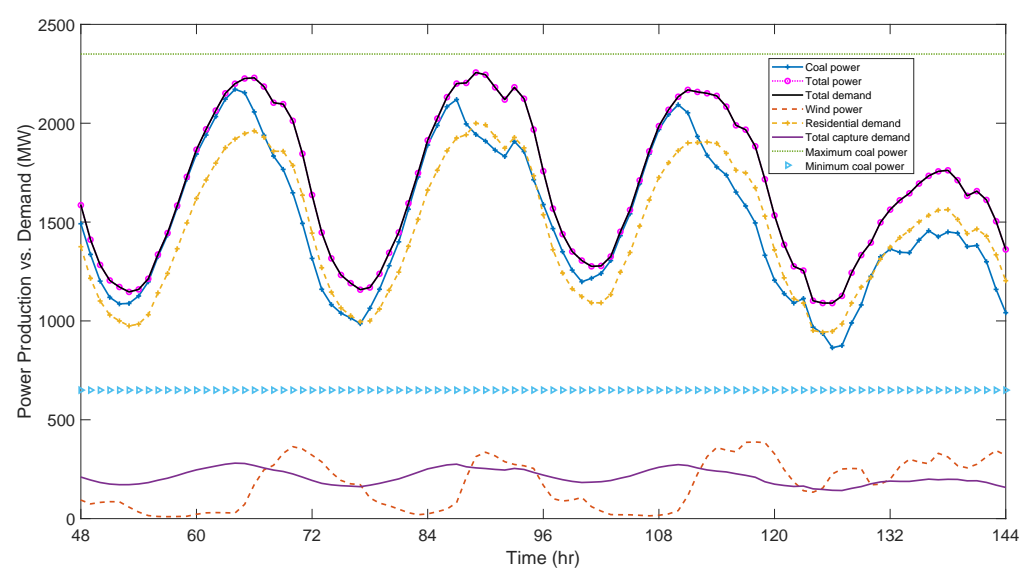

(a) Low temperature carbon capture

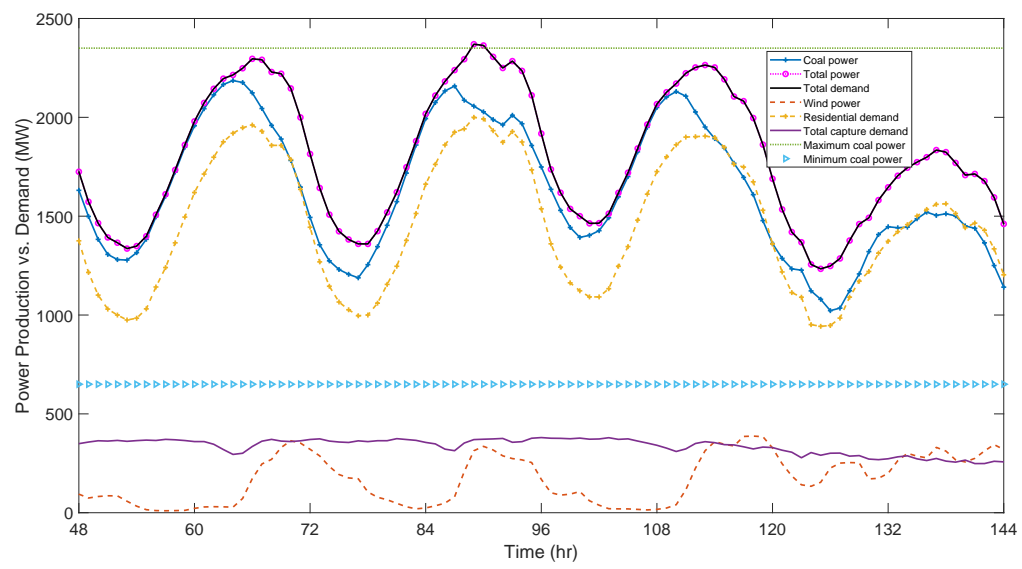

(b) Chemical absorption

Figure 7: Power vs. demand for scenario with energy storage 


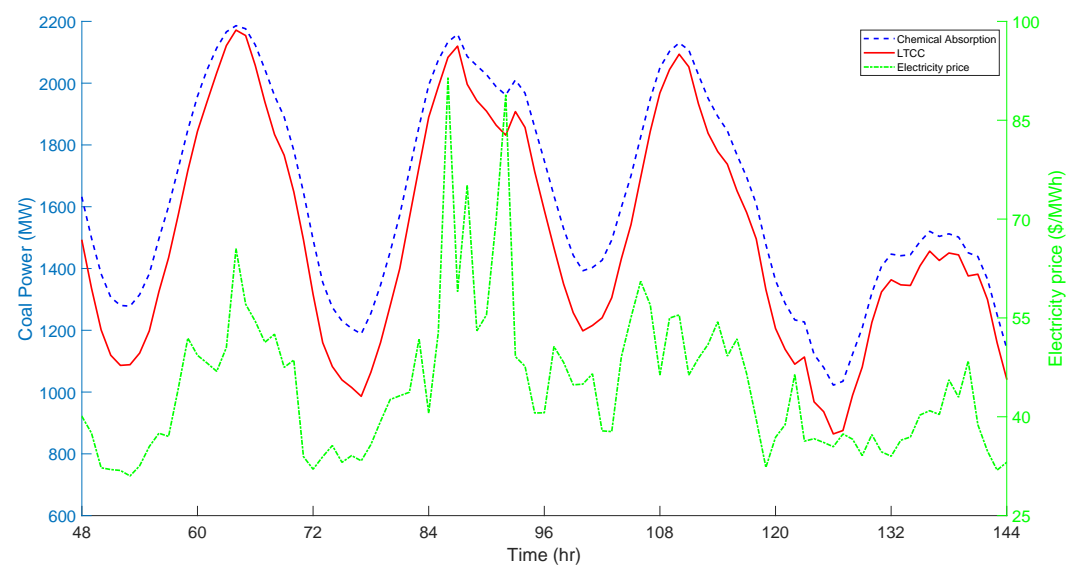

(a) Power production from coal

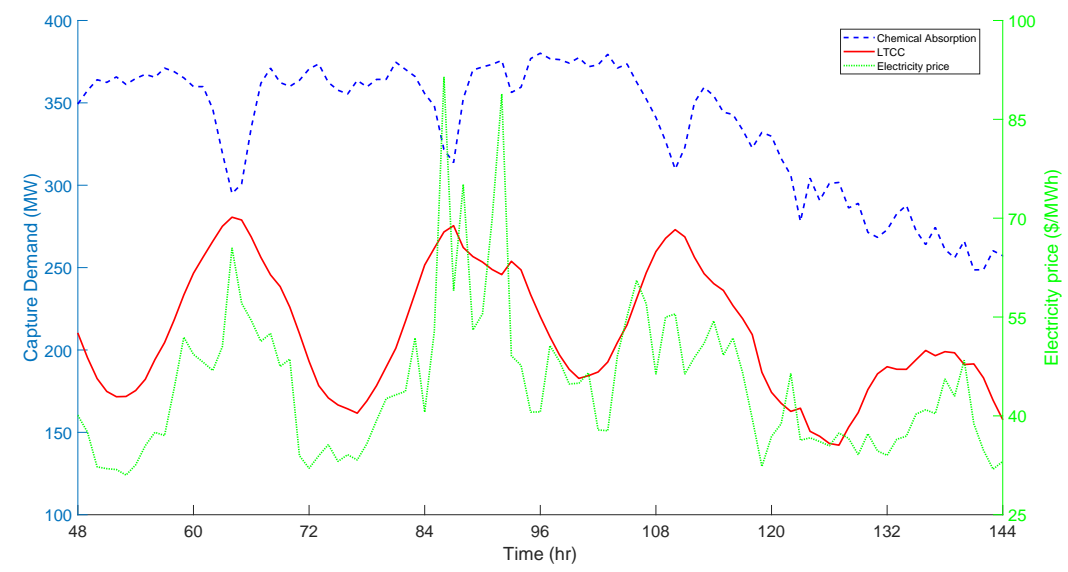

(b) Capture process overall energy demand

Figure 8: Comparison between coal power production and capture process overall energy demand for scenario with energy storage

The trend of overall energy demand of each capture system against the electricity price is shown in Figure 8b. Simulation results demonstrate that the overall energy demand of the LTCC process is $37.6 \%$ less than that of chemical absorption, when energy storage of each capture process is included. Based on a similar amount of $\mathrm{CO}_{2}$ captured in both systems, the LTCC process requires $32.34 \%$ less energy than 
chemical absorption. Similar to the case without energy storage, the lower energy demand of the LTCC process as well as the smaller portion of electricity generation from coal are because of the tight energy integration of the LTCC process and compression of the captured $\mathrm{CO}_{2}$ in liquid form. It is also observed from Figure $8 \mathrm{~b}$ that the overall energy consumption of the chemical absorption shows a decreasing trend during periods with expensive electricity while the LTCC process shows an increasing trend during the same periods. It should, however, be noted that the overall energy demand of both processes consists of different components, as shown in Figures $9 \mathrm{a}$ and $9 \mathrm{~b}$. The component directly associated with energy storage of the LTCC process is the demand of the mixed refrigerant compressor (LNG production cycle) while energy storage directly affects the stripping operation in the chemical absorption. It is obvious from Figures $9 \mathrm{a}$ and $9 \mathrm{~b}$ that the electricity demands of the mixed refrigerant compressor and stripping unit show a decreasing trend during periods with high electricity prices. The saved energy from such reduction in power demand of each capture scheme could be transferred to the power grid, resulting in more grid stability and reduced operational costs. Other components of both capture schemes, presented in Figures $9 \mathrm{a}$ and $9 \mathrm{~b}$ show an increasing trend during periods with expensive electricity. The increasing trends of these components is because they are directly related to the power and $\mathrm{CO}_{2}$ generation rates. As more power is generated during periods with expensive electricity prices (also corresponding to periods with more electricity demand), an increasing trend is observed for these components of capture process energy demand. Because the energy consumption of chemical absorption is primarily due to stripping and compression of $\mathrm{CO}_{2}$ in gas form, the trend of overall energy demand of the capture process in periods with expensive electricity is dominated by the decreasing trend of stripping operation. In the LTCC process, however, the dominant energy consuming sources are the capture process and the natural gas compressor that are directly related to power output from the plant and the generated $\mathrm{CO}_{2}$; thus, the overall energy demand of the LTCC process shows an increasing trend during periods with peak electricity prices. Table 7 provides a comparison between the electricity demand of the major energy-consuming components of each capture technology, as presented in 
Figures 1 and 2 for three levels of gross power output.

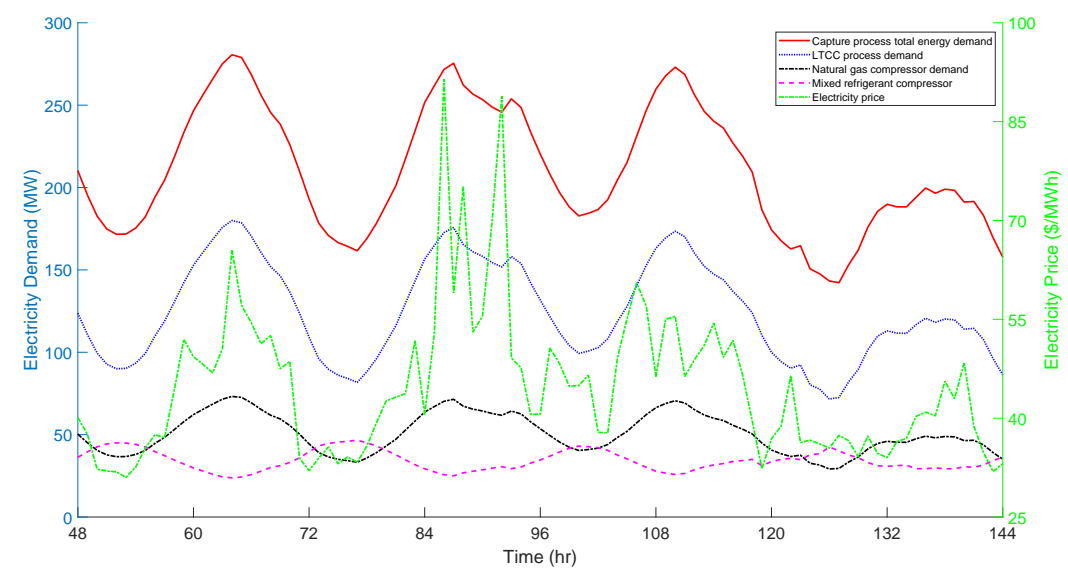

(a) Low temperature carbon capture

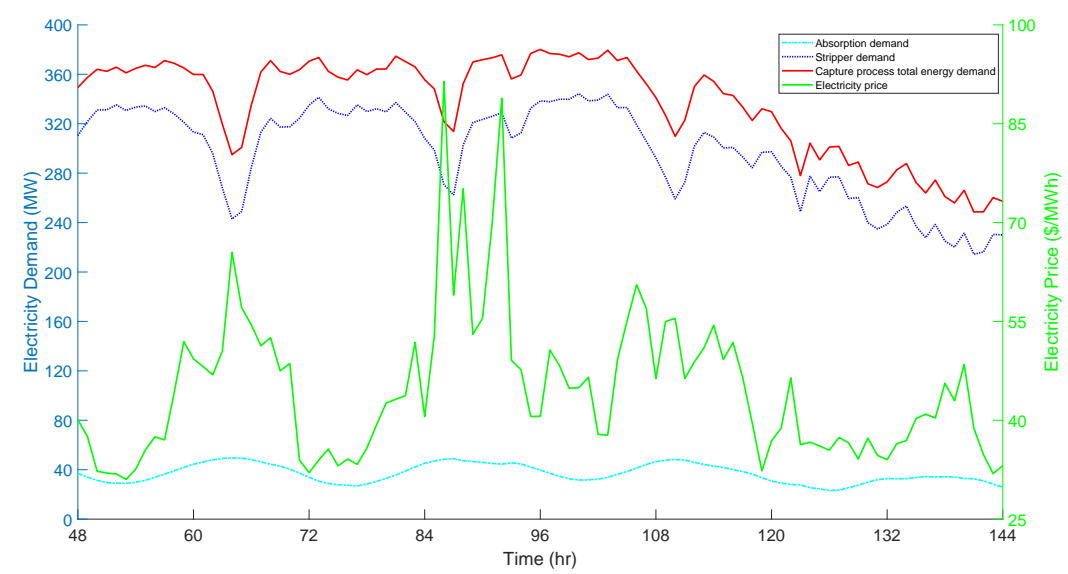

(b) Chemical absorption

Figure 9: Components of overall electricity demand of the capture processes for scenario with energy storage

Trends of the storage tanks in each capture system also provide additional insight. Figure $10 \mathrm{a}$ presents the inventory of LNG in the storage tank of the LTCC process while Figure $10 \mathrm{~b}$ shows the $\mathrm{CO}_{2}$ level in the storage tank of chemical absorption system. As observed in Figure 10a the LNG level is increased in the tank when the 
Table 7: A comparison between electricity demand $(M W)$ of major components of each carbon capture technology with energy storage at three levels of gross power output. Abbreviations are defined as NG: natural gas, MR: mixed refrigerant, Abs: absorption, Str: stripping, and Comp: compression

\begin{tabular}{|c|c|c|c|c|c|c|}
\hline \multirow{2}{*}{} & \multirow{2}{*}{ Gross power } & \multicolumn{3}{|c|}{ Low temperature carbon capture } & \multicolumn{2}{c|}{ Chemical absorption } \\
\cline { 3 - 7 } & & NG Comp. & MR Comp. & LTCC process & Abs. & Str./Comp. \\
\hline High load & 2171.7 & 73.2 & 23.8 & 180 & 49.3 & 260.9 \\
Intermediate load & 1434.6 & 48.3 & 37.2 & 118.9 & 32.5 & 326.9 \\
Low load & 1022.3 & 34.5 & 35.9 & 87.7 & 23.2 & 276.7 \\
\hline
\end{tabular}

electricity price is less expensive. This is because natural gas is imported from the pipeline during these hours, then liquefied, and stored in the storage tank. Thus, an increase in LNG level is observed during these hours. When electricity is more expensive, LNG production from pipeline natural gas is ceased and the LNG required in the LTCC process is supplied from the storage tank; thus, a decrease in the LNG level is observed. This trend also corresponds to the mixed refrigerant demand observed in Figure $9 \mathrm{a}$

For the chemical absorption system, a similar trend is observed. When electricity is less expensive, the stripping load is increased to remove $\mathrm{CO}_{2}$ from the rich Amine solution. This results in a decrease in the $\mathrm{CO}_{2}$ inventory in the storage tank. During periods with more expensive electricity, the stripping load is reduced, resulting in an inventory buildup in the storage tank. The trend of $\mathrm{CO}_{2}$ inventory in the storage tank is also consistent with that of stripping electricity demand shown in Figure $9 \mathrm{~b}$ 


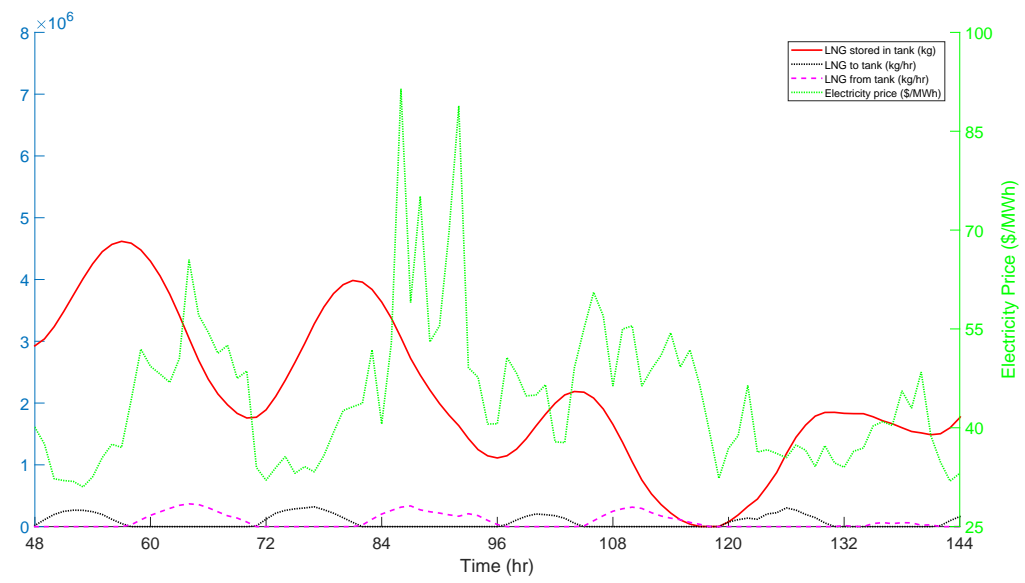

(a) LNG inventory (LTCC process)

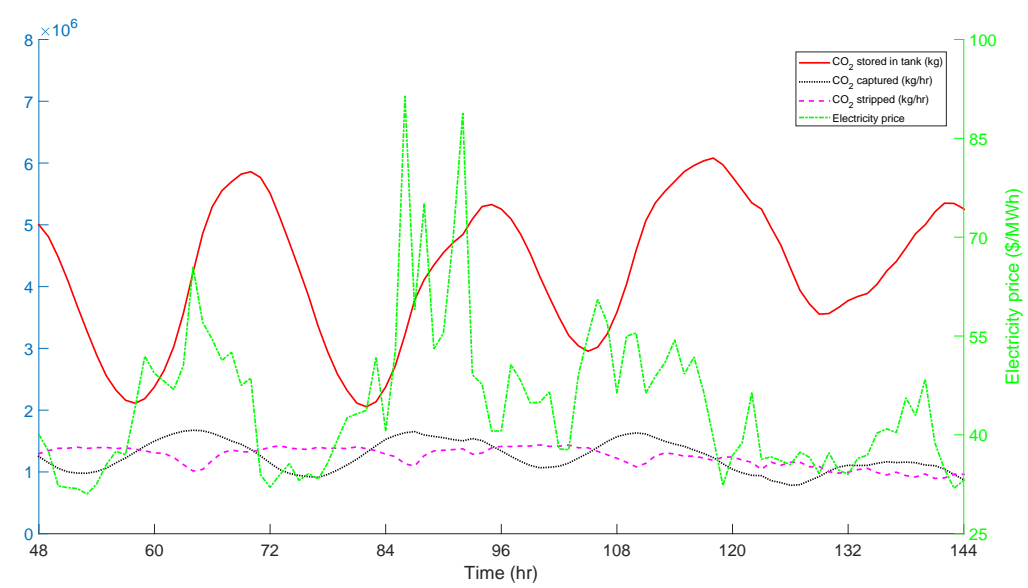

(b) $\mathrm{CO}_{2}$ inventory (chemical absorption)

Figure 10: Inventory of the storage tank in each capture process

The operating cost associated with the LTCC process is $16.16 \%$ less than the chemical absorption, when the energy storage of each technology is included in the analysis. Taking into account the total $\mathrm{CO}_{2}$ captured in each process over the simulation time, it is observed that the cost associated with the LTCC process is $9.09 \%$ cheaper than the chemical absorption to capture a similar amount of $\mathrm{CO}_{2}$. Additionally, the operational costs per $\mathrm{kg}$ of captured $\mathrm{CO}_{2}$ for the scenario with energy stor- 
age are $5.7 \%$ and $0.82 \%$ lower for the LTCC and chemical absorption, respectively, when compared to the similar systems without energy storage. Table 8 provides a summary of the results for both capture processes with energy storage.

Table 8: LTCC to chemical absorption parameter ratio for scenarios with and without energy storage

\begin{tabular}{ccc}
\hline Parameter ratio & $\begin{array}{c}\text { Without } \\
\text { Storage }\end{array}$ & $\begin{array}{c}\text { With } \\
\text { Storage }\end{array}$ \\
\hline Overall coal power (\%) & 94.94 & 92.22 \\
\hline Overall capture energy demand & 79.5 & 67.66 \\
per $k g$ captured $\mathrm{CO}_{2}(\%)$ & & \\
\hline Total operating cost & 95.70 & 90.91 \\
\hline per $k g$ captured $\mathrm{CO}_{2}(\%)$ & & \\
\hline
\end{tabular}

\section{Conclusion and Future Work}

This work provides a comparison between two configurations of the low temperature and chemical absorption carbon capture processes in response to dynamic inputs to the model of integrated systems of power generation and carbon capture. Dynamic inputs to the models include residential electricity demand, electricity price, and wind power availability. The objective in this study is to minimize the total operating cost associated with the integrated system of power generation and capture process while meeting the overall electricity demand. This comparison includes scenarios with and without energy storage capabilities of the low temperature carbon capture (LTCC) and chemical absorption.

In the scenario without energy storage, it is observed that both systems are able to meet the total electricity demand while $100 \%$ of the available wind power is utilized in meeting the demand. The LTCC process, however, produces $5.06 \%$ less power from the combustion of coal. Additionally, the LTCC process requires $20.5 \%$ less electricity than the chemical absorption in capturing the same amounts of carbon dioxide $\left(\mathrm{CO}_{2}\right)$. Without energy storage, it is also observed that all components of the overall electricity demand of both capture processes show an increasing trend 
during periods with peak electricity demand and price. This results in a less stable power grid and additional electricity cost to the end users. The total operating costs of integrating the power plant with the LTCC process is also $4.3 \%$ less than when it is integrated with the chemical absorption to capture a similar amount of $\mathrm{CO}_{2}$.

For the case with energy storage, it is observed that the overall electricity demand of the integrated system is supplied from a combination of wind and coal power. In this scenario, the coal power generated from the LTCC process is $7.78 \%$ less than that of chemical absorption over the simulation time while $100 \%$ of the available wind power is utilized in meeting the electricity demand. Based on similar amounts of $\mathrm{CO}_{2}$ captured in both systems, it is also observed that the LTCC process requires $32.34 \%$ less energy than that of chemical absorption. Additionally, the energy demand associated with the mixed refrigerant compressor (low temperature carbon capture) as well as the energy demand of stripping and compression units (chemical absorption) show decreasing trends during periods with expensive electricity and peak demand. The levels of liquefied natural gas and $\mathrm{CO}_{2}$ stored in the associated tank of each capture process also reveal consistent trends with the electricity demands of mixed refrigerant compressor and stripping and compression units, respectively. The saved energy from such reduction in power demand could be used to meet the electricity demand of the power grid, which results in a more stable grid and reduced electricity costs to the end users. Simulation results also reveal that integrating the power plant with the low temperature carbon capture incurs $9.09 \%$ less operational costs than when chemical absorption is used to capture the same amounts of $\mathrm{CO}_{2}$.

This paper also demonstrates the benefits of using dynamic optimization in minimizing the operational costs, independent from the type of carbon capture or power plant technology being used. The model developed in this paper responds, ahead of time, to the fluctuations anticipated for the electricity demand, electricity price, and wind power such that the total operational costs are minimized over a future horizon while satisfying all the constraints and reducing $\mathrm{CO}_{2}$ emissions. The approach used in this analysis is similar to various real-time optimization and operation scheduling efforts implemented in many industries to respond to time-varying inputs. The 
modular modeling and optimization framework developed in this work can be utilized for other similar systems, as demonstrated in [70].

While this paper provides a comparison between the performance of the LTCC and chemical absorption systems, it is important from an operational standpoint to notice that the primary consideration, when operating transiently, is the ability of equipment to handle changing flow rates. Heat exchangers and columns are especially sensitive to this. This has a profound impact on efficiency and cost since imbalanced heat exchangers and columns nearly always miss their operating set points and develop very different temperature profiles during a transient process. A significant amount of entropy is also created while cycling temperatures of equipment up and down. Most of these issues have been analyzed experimentally and theoretically in detail in $72,73,74,75,52$ with respect to the LTCC process. Future studies are also required to analyze the behavior of the chemical absorption in response to changing flow rates. However, it should be noted that these considerations for the LTCC process were not included in the models developed in this paper.

Transient operation of both systems also impact the efficiency of each process. For the LTCC process, ramping the mixed refrigerant compressor up or down negatively impacts the design operating point of the compressor. Steam turbines also work at different efficiencies when their output loads vary. The efficiency loss associated with a change in operating point should be considered in future work. Additionally, ramping the chemical absorption system also requires much larger lowpressure turbines and towers with a very high turndown ratios. Such large fluctuations in these systems will almost certainly decrease system efficiency and increase the capital costs. Thus, it is critical to consider the consequence of such fluctuations in future work. Finally, the significant additional capital costs of retrofitting the capture plants to existing power plants could be a major deterrent to the widespread implementation of carbon capture technologies. Optimization of the integrated system, while considering the capital costs, is the focus of future study. 


\section{Acknowledgments}

This work was partially funded by the University of Utah and the authors are grateful for their support. They are also thankful for the support of Stuart Cohen at National Renewable Energy Laboratory on the chemical absorption model.

\section{References}

[1] Annual Energy Outlook 2017 with projections to 2050, Tech. rep., https: //www.eia.gov/outlooks/aeo/pdf/0383(2017).pdf (accessed December 2017).

[2] Inventory of US Greenhouse Gas Emissions and Sinks 1990-2015, Tech. rep., https://www.epa.gov/sites/production/files/2017-02/documents/ 2017_complete_report.pdf (accessed December 2017).

[3] Conclusions of the IPCC Working Group I Fifth Assessment Report, AR4, SREX and SRREN, Tech. rep., http://www.ipcc.ch/news_and_events/ docs/COP19/COP19_final_presentation.pdf (accessed December 2017).

[4] A European strategic energy technology plan (SET-PLAN) towards a low carbon future, Tech. rep., http://eur-lex.europa.eu/legal-content/EN/TXT/ PDF/?uri=CELEX : 52007DC0723\&from=EN, (accessed May 2017).

[5] Climate summit 2014, Tech. rep., http://www.un.org/climatechange/ summit/2014/09/2014-climate-change-summary-chairs-summary/ (accessed May 2017).

[6] S. M. Safdarnejad, J. D. Hedengren, L. L. Baxter, Dynamic optimization of a hybrid system of energy-storing cryogenic carbon capture and a baseline power generation unit, Applied Energy 172 (2016) 66 - 79. doi:10.1016/j. apenergy.2016.03.074

[7] C.-C. Cormos, Integrated assessment of IGCC power generation technology with carbon capture and storage CCS, Energy 42 (1) (2012) 434 - 445. doi: $10.1016 / j$. energy $\cdot 2012.03 .025$. 
[8] C.-C. Cormos, P. S. Agachi, Integrated assessment of carbon capture and storage technologies in coal-based power generation using CAPE tools, Computer Aided Chemical Engineering 30 (2012) 56 - 60. doi:10.1016/ B978-0-444-59519-5.50012-5.

[9] M. Gazzani, D. M. Turi, A. F. Ghoniem, E. Macchi, G. Manzolini, Technoeconomic assessment of two novel feeding systems for a dry-feed gasifier in an IGCC plant with pd-membranes for $\mathrm{CO}_{2}$ capture, Int. J. Greenhouse Gas Control 25 (2014) 62 - 78. doi:10.1016/j.ijggc.2014.03.011.

[10] A. Gopan, B. M. Kumfer, J. Phillips, D. Thimsen, R. Smith, R. L. Axelbaum, Process design and performance analysis of a staged, pressurized oxy-combustion (SPOC) power plant for carbon capture, Appl. Energy 125 (2014) 179 - 188. doi:10.1016/j.apenergy.2014.03.032.

[11] Advancing Oxycombustion Technology for Bituminous Coal Power Plants: An R\&D Guide, Tech. rep., https://www.netl.doe.gov/ File\%20Library/Research/Energy\%20Analysis/Publications/ DOE-NETL-2010-1405FinalReport042012.pdf. (accessed May 2017).

[12] G. Xu, Y. ping Yang, J. Ding, S. Li, W. Liu, K. Zhang, Analysis and optimization of $\mathrm{CO}_{2}$ capture in an existing coal-fired power plant in china, Energy 58 (0) (2013) 117 - 127. doi:10.1016/j.energy .2013.04.012.

[13] C. A. Kang, A. R. Brandt, L. J. Durlofsky, Optimal operation of an integrated energy system including fossil fuel power generation, $\mathrm{CO}_{2}$ capture and wind, Energy 36 (12) (2011) 6806 - 6820. doi:10.1016/j . energy .2011.10.015.

[14] P. G. Brodrick, C. A. Kang, A. R. Brandt, L. J. Durlofsky, Optimization of carboncapture-enabled coal-gas-solar power generation, Energy 79 (2015) 149 - 162. doi:10.1016/j.energy.2014.11.003

[15] C. A. Kang, A. R. Brandt, L. J. Durlofsky, Optimizing heat integration in a flexible coal-natural gas power station with $\mathrm{CO}_{2}$ capture, International Journal of 
Greenhouse Gas Control 31 (2014) 138 - 152. doi:10.1016/j.ijggc. 2014. 09.019

[16] C. A. Kang, A. R. Brandt, L. J. Durlofsky, A new carbon capture proxy model for optimizing the design and time-varying operation of a coal-natural gas power station, International Journal of Greenhouse Gas Control (2015) -doi : $10.1016 / j \cdot$ ijggc.2015.11.023.

[17] H. Chalmers, M. Leach, J. Gibbins, Built-in flexibility at retrofitted power plants: What is it worth and can we afford to ignore it?, Energy Procedia 4 (2011) 2596 -2603. doi:10.1016/j .egypro.2011.02.158.

[18] S. M. Cohen, G. T. Rochelle, M. E. Webber, Optimizing post-combustion $\mathrm{CO}_{2}$ capture in response to volatile electricity prices, Int. J. Greenh. Gas Control 8 (2012) 180 - 195. doi:10.1016/j.ijggc. 2012.02.011.

[19] S. M. Cohen, G. T. Rochelle, M. E. Webber, Optimal operation of flexible postcombustion $\mathrm{CO}_{2}$ capture in response to volatile electricity prices, Energy Procedia 4 (2011) 2604-2611. doi:10.1016/j .egypro.2011.02.159

[20] S. M. Cohen, G. T. Rochelle, M. E. Webber, Turning $\mathrm{CO}_{2}$ capture on and off in response to electric grid demand: A baseline analysis of emissions and economics, ASME Journal of Energy Resources Technology 132 (2010) 021003. doi:10.1115/ES2008-54296.

[21] S. Ziaii, S. Cohen, G. T. Rochelle, T. F. Edgar, M. E. Webber, Dynamic operation of amine scrubbing in response to electricity demand and pricing, Energy Procedia 1 (1) (2009) 4047-4053. doi:10.1016/j . egypro.2009.02 . 211.

[22] H. Chalmers, J. Gibbins, Initial evaluation of the impact of post-combustion capture of carbon dioxide on supercritical pulverised coal power plant part load performance, Fuel 86 (14) (2007) 2109 - 2123. doi:10.1016/j.fuel. 2007.01 .028 
[23] H. Gerbelová, P. Versteeg, C. S. Ioakimidis, P. Ferrão, The effect of retrofitting Portuguese fossil fuel power plants with CCS, Appl. Energ. 101 (2013) 280 - 287. doi:10.1016/j.apenergy.2012.04.014.

[24] B. Belaissaoui, G. Cabot, M.-S. Cabot, D. Willson, E. Favre, $\mathrm{CO}_{2}$ capture for gas turbines: an integrated energy-efficient process combining combustion in oxygen-enriched air, flue gas recirculation, and membrane separation, Chem. Eng. Sci. 97 (2013) 256 - 263. doi:10.1016/j .ces. 2013.04.027.

[25] M. Rezakazemi, M. Sadrzadeh, T. Matsuura, Thermally stable polymers for advanced high-performance gas separation membranes, Progress in Energy and Combustion Science 66 (2018) 1-41. doi :10.1016/j.pecs.2017.11.002

[26] M. Rezakazemi, A. E. Amooghin, M. M. Montazer-Rahmati, A. F. Ismail, T. Matsuura, State-of-the-art membrane based $\mathrm{CO}_{2}$ separation using mixed matrix membranes (MMMs): An overview on current status and future directions, Progress in Polymer Science 39 (5) (2014) 817 - 861. doi:10.1016/j. progpolymsci.2014.01.003

[27] Q. Chen, C. Kang, Q. Xia, Modeling flexible operation mechanism of hbox $\mathrm{CO}_{2}$ capture power plant and its effects on power-system operation, IEEE Transactions on Energy Conversion 25 (3) (2010) 853-861. doi : 10.1109/TEC. 2010. 2051948

[28] N. M. Dowell, N. Samsatli, N. Shah, Dynamic modelling and analysis of an amine-based post-combustion $\mathrm{CO}_{2}$ capture absorption column, International Journal of Greenhouse Gas Control 12 (2013) 247 - 258. doi:10.1016/j . ijggc.2012.10.013.

[29] S. Posch, M. Haider, Dynamic modeling of $\mathrm{CO}_{2}$ absorption from coal-fired power plants into an aqueous monoethanolamine solution, Chemical Engineering Research and Design 91 (6) (2013) 977 - 987. doi:10.1016/j . cherd. 2012.09 .016 . 
[30] H. Liang, Z. Xu, F. Si, Economic analysis of amine based carbon dioxide capture system with bi-pressure stripper in supercritical coal-fired power plant, International Journal of Greenhouse Gas Control 5 (4) (2011) 702 - 709. doi: 10.1016/j.ijggc.2011.01.004.

[31] M. Bui, I. Gunawan, V. Verheyen, P. Feron, E. Meuleman, S. Adeloju, Dynamic modelling and optimisation of flexible operation in post-combustion $\mathrm{CO}_{2}$ capture plants - A review, Computers \& Chemical Engineering 61 (2014) 245 - 265. doi:10.1016/j.compchemeng.2013.11.015

[32] P.-A. Bouillon, S. Hennes, C. Mahieux, ECO2: Post-combustion or oxyfuel - A comparison between coal power plants with integrated $\mathrm{CO}_{2}$ capture, Energy Procedia 1 (1) (2009) 4015 - 4022, Greenhouse Gas Control Technologies 9. doi:10.1016/j.egypro.2009.02.207

[33] C. Kunze, H. Spliethoff, Assessment of oxy-fuel, pre- and post-combustionbased carbon capture for future IGCC plants, Applied Energy 94 (2012) 109 116. doi:10.1016/j.apenergy . 2012.01.013

[34] J. Cristóbal, G. Guillén-Gosálbez, L. Jiménez, A. Irabien, Multi-objective optimization of coal-fired electricity production with $\mathrm{CO}_{2}$ capture, Applied Energy 98 (2012) 266 - 272. doi:10.1016/j . apenergy . 2012 .03.036

[35] D. P. Hanak, A. J. Kolios, V. Manovic, Comparison of probabilistic performance of calcium looping and chemical solvent scrubbing retrofits for $\mathrm{CO}_{2}$ capture from coal-fired power plant, Applied Energy 172 (2016) 323 - 336. doi:10. 1016/j.apenergy.2016.03.102.

[36] A. Bhave, R. H. Taylor, P. Fennell, W. R. Livingston, N. Shah, N. M. Dowell, J. Dennis, M. Kraft, M. Pourkashanian, M. Insa, J. Jones, N. Burdett, A. Bauen, C. Beal, A. Smallbone, J. Akroyd, Screening and techno-economic assessment of biomass-based power generation with CCS technologies to meet $2050 \mathrm{CO}_{2}$ targets, Applied Energy 190 (2017) 481 - 489. doi:10.1016/j.apenergy. 2016.12 .120 
[37] A. Skorek-Osikowska, ÅĄukasz Bartela, J. Kotowicz, Thermodynamic and ecological assessment of selected coal - fired power plants integrated with carbon dioxide capture, Applied Energy 200 (2017) 73 - 88. doi:10.1016/j. apenergy.2017.05.055

[38] J. Davison, Performance and costs of power plants with capture and storage of $\mathrm{CO}_{2}$, Energy 32 (7) (2007) 1163 - 1176. doi:10.1016/j.energy . 2006.07. 039 .

[39] S. Vasudevan, S. Farooq, I. A. Karimi, M. Saeys, M. C. Quah, R. Agrawal, Energy penalty estimates for $\mathrm{CO}_{2}$ capture: Comparison between fuel types and capture-combustion modes, Energy 103 (2016) 709 - 714. doi:10.1016/j. energy.2016.02.154

[40] A. S. R. Subramanian, K. Jordal, R. Anantharaman, B. A. Hagen, S. Roussanaly, A comparison of post-combustion capture technologies for the NGCC, Energy Procedia 114 (2017) 2631 - 2641, 13th International Conference on Greenhouse Gas Control Technologies, GHGT-13, 14-18 November 2016, Lausanne, Switzerland. doi:10.1016/j.egypro.2017.03.1436.

[41] S. Mukherjee, P. Kumar, A. Yang, P. Fennell, Energy and exergy analysis of chemical looping combustion technology and comparison with pre-combustion and oxy-fuel combustion technologies for $\mathrm{CO}_{2}$ capture, Journal of Environmental Chemical Engineering 3 (3) (2015) 2104 -2114. doi:10.1016/j j jece. 2015. 07.018

[42] A.-M. Cormos, C.-C. Cormos, Techno-economic evaluations of postcombustion $\mathrm{CO}_{2}$ capture from sub- and super-critical circulated fluidised bed combustion (CFBC) power plants, Applied Thermal Engineering 127 (2017) 106 - 115. doi:10.1016/j .applthermaleng.2017.08.009.

[43] P. Eser, A. Singh, N. Chokani, R. S. Abhari, Effect of increased renewables generation on operation of thermal power plants, Applied Energy 164 (2016) 723 732. doi:10.1016/j . apenergy.2015.12.017 
[44] J. Yan, Y. Zhai, P. Wijayatunga, A. M. Mohamed, P. E. Campana, Renewable energy integration with mini/micro-grids, Applied Energy 201 (2017) 241 - 244. doi:10.1016/j.apenergy ·2017.05.160.

[45] J. Wang, A. J. Conejo, C. Wang, J. Yan, Smart grids, renewable energy integration, and climate change mitigation - future electric energy systems, Applied Energy 96 (2012) 1-3. doi:10.1016/j . apenergy . 2012.03.014

[46] M. Kubik, P. Coker, J. Barlow, Increasing thermal plant flexibility in a high renewables power system, Applied Energy 154 (2015) 102 - 111. doi:10.1016/ j.apenergy.2015.04.063.

[47] M. Jensen, Energy Processes Enabled by Cryogenic Carbon Capture, Ph.D. thesis, Brigham Young University (2015).

[48] M. J. Jensen, C. S. Russell, D. Bergeson, C. D. Hoeger, D. J. Frankman, C. S. Bence, L. L. Baxter, Prediction and validation of external cooling loop cryogenic carbon capture (CCC-ECL) for full-scale coal-fired power plant retrofit, Int. J. Greenhouse Gas Control 42 (2015) 200 - 212. doi:10.1016/j.ijggc. 2015.04.009,

[49] A. Sayre, D. Frankman, A. Baxter, K. Stitt, L. Baxter, Field testing of cryogenic carbon capture, in: Carbon Management Technology Conference, Houston, TX, 2017. doi:10.7122/486652-MS.

[50] F. Fazlollahi, A. Bown, E. Ebrahimzadeh, L. L. Baxter, Design and analysis of the natural gas liquefaction optimization process- (CCC-ES) (energy storage of cryogenic carbon capture), Energy 90, Part 1 (2015) $244-257$. doi:10.1016/ j.energy.2015.05.139.

[51] F. Fazlollahi, A. Bown, E. Ebrahimzadeh, L. L. Baxter, Transient natural gas liquefaction and its application to CCC-ES (energy storage with cryogenic carbon capture), Energy 103 (Supplement C) (2016) 369 - 384. doi:10.1016/j . energy.2016.02.109 
[52] F. Fazlollahi, A. Bown, S. Saeidi, E. Ebrahimzadeh, L. L. Baxter, Transient natural gas liquefaction process comparison-dynamic heat exchanger under transient changes in flow, Applied Thermal Engineering 109 (Part A) (2016) 775 - 788. doi:10.1016/j.applthermaleng.2016.08.082.

[53] S. M. Safdarnejad, J. D. Hedengren, L. L. Baxter, Plant-level dynamic optimization of cryogenic carbon capture with conventional and renewable power sources, Applied Energy 149 (2015) 354 - 366. doi:10.1016/j.apenergy . 2015.03 .100 .

[54] S. M. Safdarnejad, J. D. Hedengren, L. L. Baxter, L. Kennington, Investigating the impact of cryogenic carbon capture on the performance of power plants, in: Proceedings of the American Control Conference (ACC), Chicago, IL, 2015, pp. 5016-5021. doi:10.1109/ACC.2015.7172120.

[55] S. M. Cohen, A Techno-economic Plant- and Grid-Level Assessment of Flexible $\mathrm{CO}_{2}$ Capture, Ph.D. thesis, The University of Texas at Austin (2012).

[56] J. D. Jansen, L. J. Durlofsky, Use of reduced-order models in well control optimization, Optimization and Engineering 18 (1) (2017) 105-132. doi:10.1007/ s11081-016-9313-6.

[57] Cost and Performance Baseline for Fossil Energy Plants Volume 1: Bituminous Coal and Natural Gas to Electricity, Tech. rep., https: //www.nrc.gov/docs/ ML1217/ML12170A423.pdf, (accessed May 2018).

[58] S. M. Safdarnejad, J. D. Hedengren, L. L. Baxter, Dynamic optimization of a hybrid system of energy-storing cryogenic carbon capture and a baseline power generation unit, Applied Energy 172 (2016) 66-79.

[59] California Independent System Operator (CAISO), System Demand, CAISO Demand Forecast, http: //oasis. caiso.com/. (accessed February 2015).

[60] LCG consulting website, http://www.energyonline.com/Data/ GenericData.aspx?DataId=20\&CAISO_-_Average_Price, (accessed February 2015). 
[61] California Independent System Operator (CAISO), System Demand, Wind and Solar Forecast, http://oas is . caiso. com. (accessed February 2015).

[62] S. M. Safdarnejad, J. D. Hedengren, N. R. Lewis, E. L. Haseltine, Initialization strategies for optimization of dynamic systems, Computers \& Chemical Engineering 78 (2015) 39 - 50. doi:10.1016/j . compchemeng.2015.04.016

[63] I. Hajizadeh, M. Rashid, K. Turksoy, S. Samadi, J. Feng, N. Frantz, M. Sevil, E. Cengiz, A. Cinar, Plasma insulin estimation in people with type 1 diabetes mellitus, Ind. Eng. Chem. Res. 56 (35) (2017) 9846-9857. doi:10.1021/acs. iecr.7b01618

[64] General Algebraic Modeling System (GAMS), http://www.GAMS.com/, (accessed December 2017).

[65] J. Czyzyk, M. P. Mesnier, J. J. Moré, The neos server, IEEE Journal on Computational Science and Engineering 5 (3) (1998) 68 - 75. doi:10.1109/99.714603

[66] E. D. Dolan, The neos server 4.0 administrative guide, Technical Memorandum ANL/MCS-TM-250, Mathematics and Computer Science Division, Argonne National Laboratory (2001).

[67] I. Hajizadeh, K. Turksoy, E. Cengiz, A. Cinar, Real-time estimation of plasma insulin concentration using continuous subcutaneous glucose measurements in people with type 1 diabetes, in: American Control Conference (ACC), 2017, IEEE, 2017, pp. 5193-5198. doi:10.23919/ACC.2017.7963761.

[68] I. Hajizadeh, M. Rashid, K. Turksoy, S. Samadi, J. Feng, M. Sevili, N. Frantz, C. Lazaro, Z. Maloney, E. Littlejohn, A. Cinar, Multivariable recursive subspace identification with application to artificial pancreas systems, IFACPapersOnLine (2017) 909-914doi:10.1016/j . ifacol.2017.08.268.

[69] A. Cinar, K. Turksoy, I. Hajizadeh, Multivariable artificial pancreas method and system, US Patent App. 15/171,355 (Jun. 2 2016). 
[70] S. M. Safdarnejad, J. R. Gallacher, J. D. Hedengren, Dynamic parameter estimation and optimization for batch distillation, Computers \& Chemical Engineering 86 (2016) 18 -32. doi:10.1016/j . compchemeng. 2015.12.001.

[71] A. N. Eaton, S. M. Safdarnejad, J. D. Hedengren, K. Moffat, C. B. Hubbell, D. V. Brower, A. D. Brower, Post-installed fiber optic pressure sensors on subsea production risers for severe slugging control, in: Proceedings of the ASME 2015, $34^{\text {th }}$ International Conference on Ocean, Offshore and Arctic Engineering (OMAE), no. OMAE2015-42196, St. John's, Canada, 2015. doi:10.1115/ OMAE2015-42196

[72] E. Ebrahimzadeh, L. L. Baxter, Plant-wide control of coupled distillation columns with partial condensers, Applied Thermal Engineering 102 (2016) 785 -799. doi:10.1016/j .applthermaleng.2016.04.024

[73] E. Ebrahimzadeh, J. Matagi, F. Fazlollahi, L. L. Baxter, Alternative extractive distillation system for $\mathrm{CO}_{2}$ - ethane azeotrope separation in enhanced oil recovery processes, Applied Thermal Engineering 96 (2016) 39 - 47. doi:10.1016/j . applthermaleng.2015.11.082

[74] E. Ebrahimzadeh, P. Wilding, D. Frankman, F. Fazlollahi, L. L. Baxter, Theoretical and experimental analysis of dynamic heat exchanger: Retrofit configuration, Energy 96 (2016) 545 - 560. doi : 10 . 1016/j . energy . 2015 . 12 . 068 .

[75] E. Ebrahimzadeh, P. Wilding, D. Frankman, F. Fazlollahi, L. L. Baxter, Theoretical and experimental analysis of dynamic plate heat exchanger: Nonretrofit configuration, Applied Thermal Engineering 93 (2016) 1006 - 1019. doi:10.1016/j.applthermaleng.2015.10.017. 